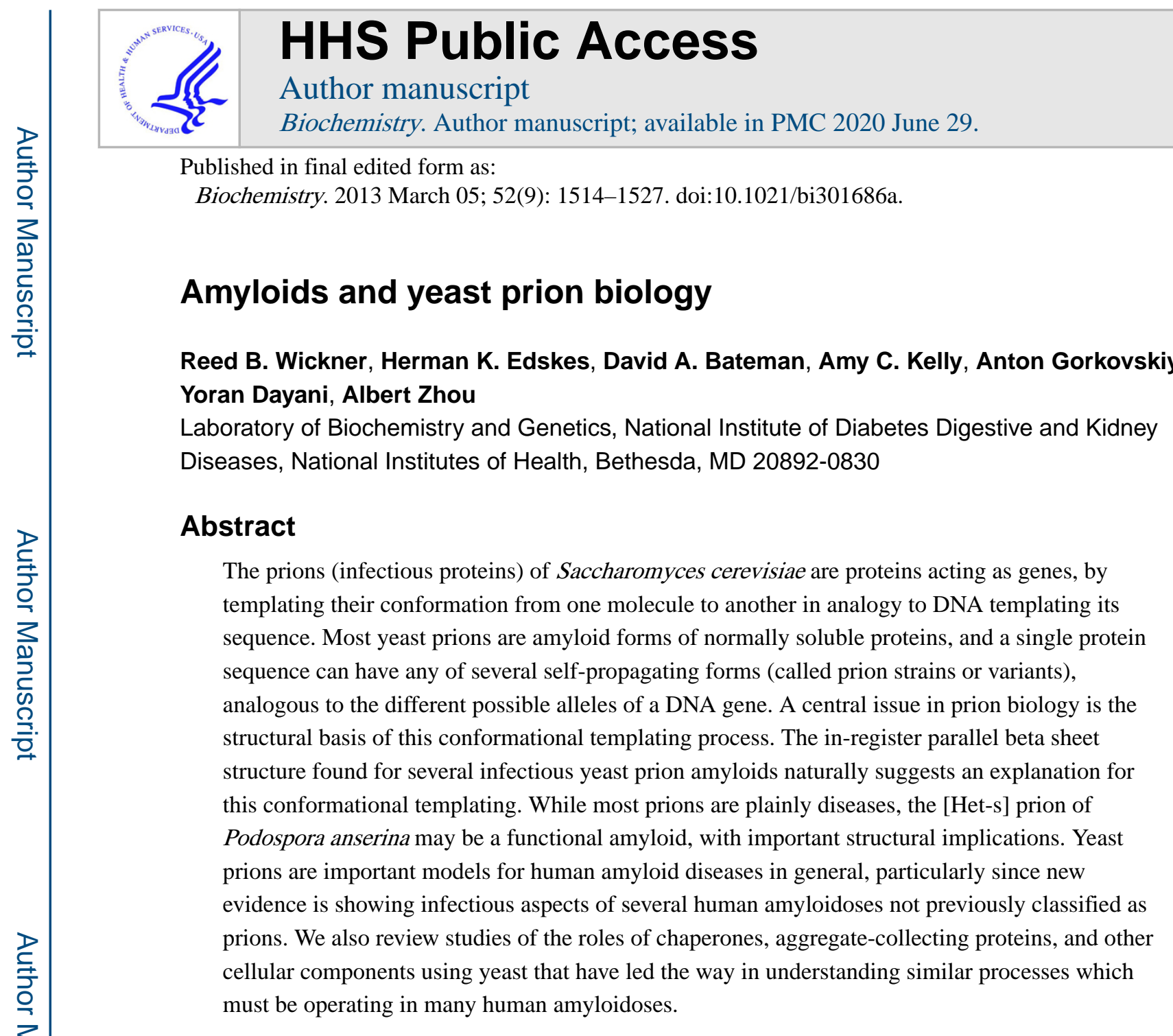

A 'prion' is an infectious protein, able to transmit a trait or a disease without the need for an accompanying nucleic acid. The concept has its origins in studies of the mammalian transmissible spongiform encephalopathies (TSEs), uniformly fatal infectious neurodegenerative diseases $(1,2)$. The TSEs are characterized by the accumulation of an altered form of the cell surface PrP protein, and numerous studies have shown that this protein is the key component of the infectious material. However, recently, evidence has emerged that PrP is not by itself sufficient for full infectivity (3), and that a phospholipid component is also necessary and affects specificity of the infectious agent (4).

The long-known yeast non-chromosomal genetic elements [URE3] and [PSI+] $(5,6)$ were shown to be prions of Ure2p and Sup35p based on genetic properties paradoxical for nucleic acid replicons, but expected for prions (Fig. 1)(7). Specifically, (a) overproduction of the putative prion protein resulted in $\sim 100$-fold increase in the frequency with which the prion arose, (b) even if the prion was cured from a strain, the same prion could (rarely) arise in the cured strain and (c) the phenotype due to the prion was the same or similar to the phenotype of a mutant in the gene for the prion protein — and mutants in that gene fail to propagate the

Contact information: Bldg. 8, Room 225, NIH, 8 Center Drive MSC 0830, Bethesda, MD 20892-0830, Phone: 301-496-3452, Fax: 301-402-0240,wickner@helix.nih.gov. 
prion (7). The phenotype relation (c) is true if the prion produces effects due to the inactivity of the protein, but not if it produces a novel or toxic effect (as will be seen below for prions $[\mathrm{PIN+}]$ and [ISP+] and toxic variants of [PSI+] or [URE3]).

The yeast prions are proteins acting as genes, transmitting information that determine phenotypes both vertically (to progeny cells) and horizontally (by cytoplasmic mixing to a neighboring cell) (7). The mechanism by which a protein transmits genetic information has long been the central puzzle of the prion field, a puzzle to which we have suggested a solution (below and refs. $(8,9)$ ). If "epigenetic" is defined as a heritable change not involving a change in DNA sequence, then yeast prions certainly formally qualify, although in no case have the chromatin changes central to most epigenetic phenomena been implicated in any prion. Here we review the central developments in the yeast prion field, focusing on the structure of prion amyloids, the biology of yeast prions and, particularly, the relation of the structures to the biology.

\section{Prion domains.}

Ure $2 p$ is a regulator of nitrogen catabolism, shutting off genes for the enzymes and transporters needed for utilization of poor nitrogen sources when a good nitrogen source is available. Sup35p is a subunit (with Sup45p) of the translation termination factor, stopping translation and releasing the completed peptide from the final tRNA. The parts of Ure2p and Sup35p involved in prion formation and propagation are restricted to their $\mathrm{N}$-terminal domains (Fig. 2), both of which are $\mathrm{Q} / \mathrm{N}$ rich (10-12). These regions are called the prion domains, as they are both necessary and sufficient for prion propagation in vivo. The [URE3] prion can propagate in the complete absence of the C-terminal domain (12), and [PSI+] can propagate with the N-terminal domain of Sup35p expressed separately from the essential C-terminal domain (10). The Ure2p and Sup35p prion domains are both rich in $\mathrm{N}$ and $\mathrm{Q}$ residues, as are most yeast prion domains (see below), but the HET-s and Mod5p prion domains are interesting exceptions (see below; $(13,14)$ ).

The 'prion domain' designation may be unfortunate in that it has suggested to some that the sole function of these domains is prion propagation. In fact, the Ure2p prion domain is necessary for protecting the protein from degradation in vivo (15), and the Sup35p prion domain links the general mRNA turnover systems to translation termination via interactions with the polyA binding protein and the polyA degrading enzyme (16). While the prion domains are sufficient for prion propagation, deletions of the C-terminal domains of Ure $2 p$ or Sup35p dramatically increase the frequency of prion formation $(11,17)$, perhaps by destabilizing the prion domain.

\section{Most prions are self-propagating amyloids.}

Amyloid is a filamentous polymer of protein monomers with a largely $\beta$-sheet structure in which the $\beta$ strands run perpendicular to the long axis of the filament (Fig. 3). Amyloid is a highly ordered aggregate characterized by relative protease-resistance and special dyebinding characteristics. Amyloid filaments of many different proteins are prominent features 
of human diseases, including Alzheimer's disease, type II diabetes, Parkinson's disease, senile amyloidosis and the prion diseases.

The protease-resistance of Ure2p in [URE3] strains (11), the self-propagating aggregation of Sup $35 p$ and Ure2p in the respective prion-carrying strains and in vitro (18-20), the formation of amyloid by their prion domains (21-24), and the visualization by electron microscopy of filaments of the prion proteins in prion-containing strains $(25,26)$, all indicated that the prions are amyloid forms of the respective protein. This was conclusively demonstrated when amyloid formed in vitro by recombinant Sup35p or Ure2p or their prion domains were shown to infect yeast spheroplasts with the respective prions (27-29).

The amyloid filaments of Sup35NM (see Fig. 2) grow by addition of monomers to the ends (30), and either end of a filament can be extended, but growth from one end tends to be strongly favored $(31,32)$.

\section{Non-Amyloid prions.}

The definition of 'prion' does not require that amyloid be involved, and at least one nonamyloid prion has been found. Zubenko and Jones showed that vacuolar protease B is normally activated by cleavage of its inactive precursor by protease A. However, in the absence of protease A, active protease B can activate its own precursor, although this reaction quickly dies out as cells grow on glucose (33). However, growing cells on glycerol, which does not repress levels of protease $\mathrm{B}$, allows this self-activation to continue indefinitely (34). In this system, active protease B acts as a prion, showing nonchromosomal inheritance, arising at increased frequency when the precursor is transiently over expressed, and requiring the $P R B 1$ gene for its propagation (34). This is a prion which is clearly important for survival: in the absence of protease A, cells without the prion die quickly in stationary phase and are unable to go through meiosis and spore formation (34).

[GAR] (glucosamine resistant) is a non-chromosomal genetic element making cells resistant to growth inhibition by glucosamine (35). [GAR] generation is stimulated by over expression of Std1p, and is lost from the double mutant deleted for a part of PMA1 and for $S T D 1$ (36). Pmalp is the major plasma membrane proton pump and Std1p is involved in regulation of glucose metabolism. It is proposed that [GAR] is a functional prion (36), but neither the mechanism of self-propagation nor the mechanism of glucosamine resistance is understood.

\section{The spectrum of yeast and fungal prions.}

The [Het-s] prion of the filamentous fungus Podospora anserina is involved in heterokaryon incompatibility, a recognition of self phenomenon (37). Two converging fungal colonies will fuse (form heterokaryons) only if they have identical alleles at about a dozen loci (het loci). A difference at even one het locus results in a programmed cell death and failure to fuse, perhaps to protect against the spread of detrimental fungal viruses (38). The het-s gene has alleles het-s (encoding HET-s, the protein whose amyloid is the basis of the [Het-s] prion) and het-S (encoding HET-S). Cell fusions between het-s [Het-s] and het-S cells lead to a programmed cell death. Demonstration of prion infection by amyloid of recombinant HET-s 
protein (and not by non-specific aggregates or the soluble protein) was the first such demonstration for any prion (39). As described below, the similarities and contrasts between the well-studied [Het-s] system and the yeast prion systems has aided in the development of our understanding of the biological and structural aspects of all prions.

The [PIN+] prion was discovered as a non-chromosomal gene needed for [PSI+]-inducibility by over expression of Sup35p (40), and identified as a self-propagating amyloid of Rnq1p, a protein rich in $\underline{\mathrm{N}}$ and $\mathrm{Q}$ residues whose deletion produces no phenotype so far identified (41, 42). Overproduction of many proteins with $\mathrm{Q} / \mathrm{N}$ rich domains can prime [PSI+] formation $(42,43)$, and several of these proteins - Swilp and Cyc $8 \mathrm{p}$ - have proven to form prions themselves $(44,45)$. Swilp is a component of a chromatin-remodeling complex, and the [SWI+] prion phenotype, poor growth on carbon sources other than glucose, resembles that of swil mutants (44). Cyc8p, with Tup1p, is a transcription repressor, and can form a prion, [OCT+], with a phenotype similar to that of $c y c 8$ mutations, derepression of a variety of genes (45).

[ISP+], so named because its phenotype is the reverse of that of [PSI+], antisuppression (decreased read-through of premature termination codons), is a prion of $\operatorname{Sfp} 1 \mathrm{p}(46,47)$. $\mathrm{Sfp} 1 \mathrm{p}$ is a transcription factor that promotes transcription of ribosomal protein genes and ribosome biogenesis genes (48). The [ISP+] prion, unlike sfp1 $1 \Delta$, produces an increased transcription of the SUP35 gene indicating an unique action of the prion, and explaining the antisuppressor phenotype (49). The [ISP+] prion is an amyloid form of Sfp1p, but the aggregates are located in the nucleus, not the cytoplasm, and the prion is thus only occasionally transmitted by transfer of cytoplasm from cell to cell (cytoduction) (47).

Recently, using a variant of the Pin screen of Derkatch and Liebman, Tanaka's group has discovered a new prion of $S$. cerevisiae that, surprisingly, does not have a $\mathrm{Q} / \mathrm{N}$ rich prion domain. [MOD] is an amyloid based prion of Mod5p, a tRNA isopentenyltransferase (14). This finding is particularly important because yeast prions are viewed as models of mammalian amyloidoses, only a small fraction of which involve $\mathrm{Q} / \mathrm{N}$-rich proteins. The prion core of Mod5p is unusual in its small size and having 6 of 24 residues charged. As with mutation of MOD5 (50), carrying the [MOD] prion improves growth in the presence of certain antifungal agents due to inactivation of Mod5p, but slows growth as much in the absence of the drugs as it helps in their presence (14).

A biochemical screen of $\mathrm{Q} / \mathrm{N}$ rich yeast proteins revealed a number of prion candidates, one of which, Mot3p, was shown to form a prion, called [MOT3+] (51). Mot3p is a transcription factor repressing ergosterol biosynthesis, is required for normal vacuolar fusion, and mutants show defective growth at $\mathrm{pH} 8$ and synthetic lethality with a vacuolar protein sorting gene, VPS41 (52). A mot3A strain grows slowly, is respiratory deficient and is hypersensitive to stress $(53,54)$. [MOT3+] strains were found to be relatively resistant to Congo red and calcofluor white (51), but other phenotypes have not yet been examined. 


\section{Prion variants: one protein sequence can propagate several different conformations.}

One prominent feature of mammalian and yeast prions is the existence of prion 'strains' or 'variants'. Scrapie strains with dramatically different incubation periods and distribution of brain lesions were recognized quite early. Variants of the yeast prions with differences in stability of propagation, intensity of phenotype, response to overproduction or depletion of chaperones, or ability to cross transmission barriers due to sequence differences, have been described (55-62). Variants or strains are terms reserved for the same sequence propagating prions with different biological or biochemical properties. Two prions based on different protein sequences are different prions. Variants are clearly due to structural differences between the variant amyloids (e.g., ref. $(28,63)$ ), but for no prion variant is the precise amyloid structure known.

\section{Structural biology by genetics.}

In an effort to show that the sequence of the Ure2p prion domain was important for its ability to support prion formation, residues 2 to 89 were randomly shuffled, leaving the amino acid composition and codon usage unchanged (64). Unexpectedly, each of the five shuffled sequences examined readily formed amyloid in vitro and prions in vivo (64). The presence of oligopeptide repeats in the Sup35p prion domain had been interpreted as central to prion formation by that molecule because PrP has similar repeats. It was thus even more surprising that shuffling just the repeats (residues 40 to 114) or the entire prion domain (residues 3 to 114) of Sup35p likewise did not prevent prion formation $(65,66)$. Substituting the Sup35p repeat domain with that of PrP allows prion formation (67), and shuffling the repeats in such a construct also does not impair prion formation (66).

This approach has been further used to examine what amino acids favor, and which retard prion formation by substituting a segment of one of the shuffled Sup35 prion domains with random peptides and examining the effect on prion formation (68). Aromatic and hydrophobic residues were favored, and a bias against charged residues was found (68). No bias for $\mathrm{Q}$ or $\mathrm{N}$ residues was noted, perhaps because the protein was already so $\mathrm{Q} / \mathrm{N}$ rich. Using these results, an algorithm was developed that accurately 'post-dicts' the known $\mathrm{Q} / \mathrm{N}$ rich prion domains, but also was used to design two entirely new $\mathrm{Q} / \mathrm{N}$-rich prion domains, which were both shown to, in fact, form prions in vivo (69). A Q/N-rich domain designed to not form a prion indeed did not (69).

The shuffling experiments also strongly suggest an in-register parallel beta sheet structure for the prion amyloids of Ure $2 p$ and Sup35p (70). The propagation of a prion requires very nearly identical sequence in the prion domain, with just a few changes, (or even one in some cases) blocking propagation. Sup35p amyloid filaments (at least) elongate by addition of monomers (30), and this sequence-specificity implies that interactions between side chains of incoming monomers must interact with the side chains of molecules already in the chain. In an anti-parallel, beta-helix or out-of-register parallel structure, it is largely non-identical side chains that are interacting favorably to stabilize the structure. Shuffling the sequence randomly would almost certainly disrupt those interactions. But if the structure is in-register 
parallel, then identical side-chains are interacting, and shuffling only disrupts the order of the interactions, but they can still occur (70). A row of glutamines or asparagines can form a row of hydrogen bonds linking their side chains, and serine or threonine residues can have similar interactions. Aligned hydrophobic residues can likewise have favorable interactions. In each case, the residues must be aligned for these interactions to occur, so this is the force driving the formation and stabilization of the in-register parallel structure. Of course, charged residues would have unfavorable interactions if in-register, and, indeed, the prion domains of Sup35p, Ure2p and Rnq1p have very few charged residues. This predicted that prion domains, such as those of Ure2p or Sup35p, which can be shuffled, and still form prions, are likely to have an in-register parallel architecture (70).

\section{Structure of prion amyloids.}

It has been convincingly argued that almost any protein can be made to form amyloid under some condition (e.g. (71)), and the structure of amyloid formed from a given protein is very sensitive to the conditions of formation, as well as stochastic factors. Thus, it is imperative that one is studying the structure of the 'right' amyloid. Because yeast and fungal prion protein amyloids are highly infectious for yeast cells $(14,27-29,39,72)$, it is often assumed (by us as well) that the amyloid formed in vitro is primarily the infectious material. The maximum infectivity of amyloid formed from recombinant Ure2p was $1 / 3$ that of an extract normalized for the amount of Ure2p (29), probably not a significant difference in this assay. However, this is far from a demonstration that all particles are infectious. This is thus a qualification of all structural studies to date.

Because of its filamentous nature, amyloid cannot be studied structurally by X-ray crystallography or solution NMR. However, solid-state NMR (reviewed by (73)) has been particularly useful, along with other methods, in examining amyloids. Solid-state NMR can accurately measure specific interatomic distances by measuring decay of signal of specifically labeled proteins, using dipolar recoupling experiments (74). In an early application of this method to amyloid filaments of a fragment of the Abeta peptide important in Alzheimer's disease, Benziger et al. found that singly labeling the carbonyl carbon of any of several residues of this peptide showed that in each case, the closest ${ }^{13} \mathrm{C}$ neighbor to a labeled atom was $\sim 5$ angstrom distant, approximately the 4.8 angstrom expected for an inregister parallel beta sheet (see Fig. 4) (75). Tycko's group found that the full length Abeta $^{1-40}$ had the same architecture, and, using an array of solid-state NMR methods and electron microscopy, determined a detailed structure of these filaments (reviewed in (74)).

The same methods have been applied to highly infectious filaments of the yeast prion domain peptides, Ure2 $\mathrm{p}^{1-89}$, Sup35NM, and Rnq1 $\mathrm{p}^{153-405}$ (76-78), with similar results. For example, the single alanine residue in Ure $2 \mathrm{p}^{1-89}$ was $\sim 5$ angstroms from its nearest labeled neighbor, necessarily the same residue on another Ure $2 \mathrm{p}^{1-89}$ molecule, meaning the molecules were aligned (in-register) at that point. Labeling the carbonyl carbons of the three leucine residues in Ure $2 \mathrm{p}^{1-89}$ or the four valine residues gave the same result, indicating that the parallel in-register structure extends through most of the prion domain (77). Similar results were obtained labeling the isoleucine residues in the context of the full length Ure2p: those in the prion domain were in-register (79). A similar conclusion was reached using 
electron spin resonance and spin labels placed every 5 residues (80). Labeling the 15 tyrosine residues in Rnq1 ${ }^{153-405}$ showed that the nearest neighbor distance was again $\sim 5$ angstroms in each case, and dilution of labeled molecules with unlabeled molecules gave the expected increase in average distance, indicating that the nearest neighbor was in a different molecule (78). The same type of experiment gave similar results for the carbonyl-carbonlabeled tyrosine residues of Sup35NM, all of which are in the $\mathrm{N}$ domain (76). Labeling the eight leucine residues of Sup35NM showed that about half were in-register, and at least that fraction was in beta sheet conformation $(76,81)$. Since only one of the eight leucines is in the $\mathrm{N}$ domain, this shows that part of the $\mathrm{M}$ domain has the in-register parallel architecture. This result is consistent with evidence that parts of $\mathrm{M}$ affect propagation of some [PSI+] variants (82), that part of the $\mathrm{M}$ domain is protected in $\mathrm{H} / \mathrm{D}$ exchange experiments (83), that four leucine residues are immobilized in solution NMR experiments (83), and that residues in M play an important role in the intraspecies transmission barriers to [PSI+] (see below, (84)).

Mass per length measurements of infectious filaments of Ure2p (85), Sup35p $(86,87)$ and Rnq1p (87) give a value of $\sim 1$ monomer per 4.8 angstroms, as expected for an in-register parallel architecture (Fig. 4), but not for a beta helix, which would produce a value of 0.5 for a two-turn per molecule helix (such as HET-s filaments (88)) or lower still for more turns per molecule.

If the prion domains of the yeast prion proteins were one simple wide beta sheet, the filaments would be far wider by a factor or 4 or more than they appear on electron micrographs. This implies that the sheet is folded along the long axis of the filament, as shown diagramatically in Fig. 4. The in-register parallel architecture largely specifies the filament structure, but the locations of the folds may vary from one prion variant to another.

Elucidation of the structural differences between prion variants will require seeding recombinant isotope-labeled prion protein with extracts of strains carrying specific prion variants, an approach used by King in studying variants of [PSI+] (27) and by Tycko in examining filaments of $A \beta$ seeded by brain tissue from Alzheimer's patients (89).

\section{Dissenting views.}

While the data discussed above establishes the in-register parallel architecture of infectious amyloids of Sup35p, Ure2p and Rnq1p prion domains or, in the case of Ure2p, the full length protein, there are other views.

Melki's group has consistently argued for a non-beta sheet structure of Ure2p filaments with the $\mathrm{C}$-terminal domain as the core structure, and it is claimed that the protein does not change its secondary structure in forming filaments (e.g. (90)). However, X-ray fiber diffraction of filaments interpreted to show absence of beta-sheet had a dense band of scattering covering the relevant area (91), and infectivity of fibrils made by this group has not been reported. Moreover, the secondary structure of the prion domain changes from unstructured (92) to beta sheet $(24,85,93)$ on formation of amyloid. Claims (e.g., ref. (94)) that Ure2p fibrils are not protease-resistant, do not bind Congo Red (a dye relatively specific for amyloid) and have no increased beta sheet are contradicted by studies from several 
different groups $(11,24,80,85,95)$. The notion that the core of the filaments is composed of the C-terminal domain (e.g. (96)) is contradicted by the ability of amyloid of the $\mathrm{N}$-terminal domain, or this domain fused to various proteins, to efficiently infect yeast (29). Moreover, the prion domain can propagate [URE3] in vivo in cells not expressing the C-terminal part at all, being efficiently infected by cells expressing the full length protein, and efficiently passing the infection in turn to such cells (12). Further, as mentioned above, the mass per length measurements of the filaments are indicative of an in-register parallel structure (85), and are incompatible with a model in which a largely unaltered C-terminal domain is the filament core.

Lindquist's group has favored a beta-helix architecture of Sup35p filaments with head-tohead (N-terminal to N-terminal) and tail-to-tail linkage of adjacent monomers (97). A large pyrene moiety was attached to a single residue, and a shift of fluorescence emission frequency was used as an indicator of proximity of that residue to the same residue in another molecule. However, the pyrene probe is larger than the structure being examined possibly altering the amyloid structure formed, and the pyrene molecules must be in a specific relative orientation, possibly precluded by the structure of the amyloid, giving deceptive results. Moreover, deletion of the entire 'tail' region does not interfere with the propagation of many [PSI+] variants (e.g. (27)) and mass per length measurements indicate one monomer per 4.7 angstrom $(86,87)$, while the beta helix model demands a value half or less that observed, as stated above. Further discussion of these apparent disagreements may be found elsewhere (98).

While the physical evidence is sufficient to show that the Ure2p, Sup35p and Rnq1p amyloids are in-register parallel structures, this architecture also provides an explanation of how prion variant information can be propagated. An explanation for this central phenomenon has not been put forward based on either the beta-helix or Ure2C-as-core models.

\section{Mechanism of conformational templating.}

A single prion protein with a single amino acid sequence can be the basis for a wide array of prion strains or variants. This is perhaps the central mystery of prions, and was one reason many did not believe that a protein could be the carrier of an infection. The folded parallel in-register architecture of the yeast prion amyloids suggests a mechanism to explain the ability of prion filaments to template their own conformation (Fig. 4) (8).

The positive interactions between identical amino acid side chains (hydrogen bonds between aligned N, Q, S or T residues; hydrophobic interactions between aligned I, V, L, F, W, or Y residues) keep the structure in register, because these interactions can only happen if the identical side chains are aligned. Charged residues would have unfavorable interactions, but are rare in the prion domains with this architecture. These same interactions force the unstructured prion domain of the monomer joining the end of the filament to assume the same conformation as monomers already in the filament (Fig. 4). The turns of the strand (at the location of the folds of the sheet) of the molecule joining the filament must be in the same location as for the molecules already in the filament. If turns are in different locations 
in different prion variant amyloids, this mechanism can explain how each conformation (the basis of each variant) is propagated. These same interactions can reproduce, in molecules newly joining the end of the filaments, the extent of the beta sheet region and the assembly of protofilaments into multimers. The latter is the basis of the difference between two structural variants of $A \beta$ protein amyloid (73).

\section{Roles of chaperones and other cell components in prion generation, propagation and segregation.}

Although highly infectious amyloids of the yeast prions form from purified recombinant proteins spontaneously in vitro, there are many cellular components that affect their generation, propagation and segregation in vivo.

\section{Hsp104 is needed for propagation by all amyloid-based prions.}

Hsp104 is a disaggregase that works with Hsp70s and Hsp40s on denatured proteins (99), and is specifically inhibited by millimolar concentrations of guanidine in the growth medium (100-102). Hsp104 is required for the propagation of [PSI+] (103) and all other amyloid based yeast prions $(14,40,44-46,51,104)$. When Hsp104 is inhibited, prion filaments continue to grow longer, but are not split to make new filaments, so that as cells divide, the number of filaments per cell decreases until some cells with no filaments are produced, meaning that they are cured of the prion $(18,105-107)$. Thus, Hsp104 is needed for prion propagation in order to regenerate seeds by breaking long amyloid filaments into short ones (reviewed by (108)). The filament breakage reaction in vitro has been shown by several groups to require Hsp70s and Hsp40s in addition to Hsp104 (109-111), as was previously found for the in vitro disaggregation reaction (99). In vivo experiments support the involvement of Hsp70's and Hsp40's in filament breakage (112). The Hsp104 homolog from E. coli, $\mathrm{ClpB}$, can substitute for $\mathrm{Hsp} 104$ in prion propagation only in the presence of the $E$. coli $\mathrm{Hsp} 70$ homolog, indicating that the two proteins interact in the filament breakage reaction (112). Hsp104 disaggregates proteins by pulling monomers out of the aggregate through a pore in the Hsp104 hexamer $(113,114)$. The Hsp104 machinery apparently acts the same on prion filaments, extracting a prion protein monomer from the middle of the filament, thereby breaking it into two filaments (114) (Fig. 5).

\section{Overproduction of Hsp104 cures only [PSI+].}

On overproduction of Hsp104, the [PSI+] prion is cured (103), albeit not as rapidly as when the activity is inhibited with guanidine (reviewed in (108)). The mechanism of curing is apparently not the simple solubilization of the amyloid filaments, as filaments formed before Hsp104 is overproduced remain, and actually grow in size (107). Certain N-terminal mutations of Hsp104 eliminate curing of [PSI+] by over expression of Hsp104, but do not affect prion propagation or sensitivity to heat shock (115). The Hsp40 group chaperone Sis $1 \mathrm{p}$ is necessary for [PSI+] propagation (116), but some Sis1p functions are dispensable for [PSI+] propagation, but required for curing of [PSI+] by over expression of Hsp104 (117). The curing is dependent on the ubiquitin system, but not prion propagation (and Sup35p is not detectably ubiquitinated) (118). Hsp104-overproduction curing of [PSI+] requires the function of Sti1p and Cpr7p (two co-chaperones that coordinate Hsp90s with 
Hsp70s), but neither Sti1p nor Cpr7p is needed for prion propagation $(119,120)$. Thus, while the mechanism of Hsp104 overproduction curing [PSI+] remains unclear, it is unlikely to be simple resolubilization/renaturation of Sup35p from filaments, and is clearly not due to Hsp104 acting alone (108).

Recently a binding site for Hsp104 in Sup35M (residues 129-148) has been identified (111). Deletion of this short region does not prevent propagation of [PSI+], or its dependence on Hsp104, but does make [PSI+] incurable by overproduction of Hsp104 (111). It should be noted that overproduction of Hsp104 also stimulates the generation of [URE3], particularly by the Candida albicans Ure2p (121).

\section{Hsp104, damaged protein segregation and prion segregation.}

On mitotic division of yeast, most oxidatively damaged/aggregated proteins are retained in the mother cell (122). This system requires Sir2p (122), a histone deacetylase essential for normal replicative longevity in yeast (123). Hsp104 is found associated with aggregated oxidized proteins, and over expression of Hsp104 can largely compensate for the defective retention of such aggregates in the mother cell and the decreased lifespan of $\operatorname{sir} 2 \Delta$ mutants (124). These results might suggest that this system is involved in the curing of [PSI+] by overproduction of Hsp104, but aged cells do not have elevated frequencies of [PSI+] or [URE3] (125). Nonetheless, this system might be involved in handling prions.

\section{Hsp70s and Hsp40s have diverse roles in prion propagation.}

The Hsp70 family in yeast includes the soluble Ssa1p, Ssa2p, Ssa3p and Ssa4p, and the ribosome-bound Ssb1p and Ssb2p (126). Over expression of Ssa1p (a cytoplasmic soluble Hsp70) inhibits curing of [PSI+] by over expression of Hsp104 (127), a mutant of Ssa1p results in failure to stably propagate [PSI+] (128), and mutation of Ssa2p can result in loss of [URE3] $(129,130)$. Although Ssa1p and Ssa2p are nearly identical, they affect [PSI+] and [URE3] differently, a specificity that is determined by a single methyl group (Ala vs Gly at residue 83) (131). Hsp70s are involved in Hsp104's filament-breakage reaction, as discussed above, and also appear to be involved in the curing of [PSI+] by Hsp104 overproduction (108).

While the Ssa's generally promote prion propagation, the Ssb's have opposite effects. Prion generation is increased in $s s b 1 \Delta s s b 2 \Delta$ strains and Hsp104 - overproduction curing of [PSI+] is enhanced by also overproducing an Ssb protein (132).

The Hsp40s Ydj1p and Sis1p affect prion propagation, and an array of evidence indicates that these co-chaperones act by influencing Hsp70 activities (reviewed by Reidy and Masison (108)).

\section{Btn2 and Cur1 promote aggregate collection and prion curing.}

Cells have developed an array of mechanisms to deal with errant proteins, those that are misfolded, inappropriately aggregated or both. The ubiquitin-proteasome system and vacuoles degrade many proteins, and aggregates are sequestered at special cellular sites. $B T N 2$ and $C U R 1$ were isolated in a screen for high copy plasmids producing curing of 
[URE3] (59). Cells deleted for both genes had a higher [URE3] prion seed number than the parent, showed partial resistance to prion - curing agents, and an increased proportion of 'strong' [URE3] variants on de novo prion induction, suggesting that the normal levels of these proteins are also acting to limit prion propagation. In the process of curing [URE3], Btn2p and Ure2p prion aggregates show striking co-localization at a single site in the cell, analogous, it was suggested, to the mammalian aggresome (59). Neither Btn2 nor Cur1 over expression cured [PSI+], perhaps because the seed number of [PSI+] is higher than that of [URE3].

Btn1p was first identified as a homolog of human Cln3p, mutant forms of which cause Batten's disease, involving neuronal accumulation of certain complex lipids (133). BTN2 transcription was reported elevated in $b t n 1 \Delta$ cells, but this has not been a consistent finding. A dramatic elevation of $B T N 2$ and $C U R 1$ expression occurs on heat shock or several other stress conditions (134). Neither protein is a member of the recognized heat shock protein families, but both are somewhat homologous to each other and to the HOOK proteins (59, 135), involved in endocytosis in Drosophila and mammalian cells. HOOK proteins in both flies and mammals bind to HOPS vacuolar sorting complex proteins (see refs in (136)). Btn2p interacts with the yeast endocytic SNARE (membrane fusion) complex and the retromer complex (that coats vesicles from late endosomes headed for the Golgi) (136). A btn2 $\Delta$ mutant mislocalizes Yif1p (a membrane protein required for fusion of endoplasmic reticulum-derived vesicles with the Golgi) to the vacuole instead of the Golgi $(136,137)$.

Another study confirmed the prion-curing activity of overproduced Btn2p and Cur1p, and showed that both bind to Sis1p, an Hsp40, bringing it into the nucleus (134). The depletion from the cytoplasm of Sis1p was suggested as the cause of prion curing (134), as Sis1p is needed for propagation of all yeast prions studied (116).

There are two cellular sites that accumulate aggregates (prion or otherwise): one juxtanuclear and the other peripheral $(134,138,139)$. Hsp42 is necessary for gathering of aggregates at the peripheral site (139), Btn2p binds to Hsp42, and that binding is necessary for Btn2p's concentration in the peripheral site (134). Studies of these aggregate accumulation sites have often assumed that overproduced aggregated prion-forming proteins, such as Ure2p, or the prion domains of Sup35p or Rnq1p, are actually prions, and have concluded that they are observing collection of prion particles at these sites $(134,138)$. However, while overproduced prion proteins generally aggregate in most cells, only a tiny minority of cells go on to develop the corresponding prion (e.g., (7)), so those studies do show that aggregates of prion proteins are moved to the aggregation sites, but not necessarily the prion particles themselves. In contrast, Kryndushkin et al. used cells in which Ure2p was not substantially overproduced and which were known to carry the [URE3] prion, so the aggregates observed were prion aggregates, and their co-localization with Btn2 at a single cellular site shows localization of prion particles (59).

In addition to model unfolded proteins and prions, Btn2p has an effect on certain nonamyloid aggregates. Optineurin mutations are associated with amyotrophic lateral sclerosis, and expression of optineurin, particularly those mutants, is toxic for $S$. cerevisiae (140). Overproduction of Btn2p relieves and btn $2 \Delta$ exacerbates this toxicity, and optineurin 
aggregates coincide perfectly with Btn2p, indicating a role for Btn2p in relieving the toxicity of these aggregates (140).

It is clear that Btn2p and Cur1p have a physiological role in responding to abnormal protein aggregates, segregating them from the rest of the cell, much as does the mammalian aggresome. The mammalian HOOK proteins, homologous to Btn2p and Cur1p, are not yet known to have such a function. Btn2p has another function, in endocytosis and vesicle movement between organelles. It will be of interest to know if these functions are two aspects of a single activity or not.

\section{Are yeast prions a bane or a benefit?}

Because mammalian prions are uniformly fatal, there has never been a doubt that they are diseases. If yeast prions were uniformly fatal, they would probably not have been discovered. We will see below that there are indeed lethal forms of yeast prions. The fact that the [Het-s] prion is necessary for in an apparently normal fungal function, heterokaryon incompatibility (38), led us to suggest that this was the first example of a beneficial prion (141). It was then reported that the [PSI+] prion made yeast cells more resistant to heat or high ethanol stress, suggesting a benefit to the host (142), but subsequent studies did not support this conclusion (143). Rather, it was found that of the dozens of conditions tested, there was none that always favored [PSI+] over [psi-] cells (143). When differences were noted, $3 / 4$ of such differences were [psi-] growing better than [PSI+], but genetic background made these results variable. However, even the minority of cases in which a particular genetic background - growth condition combination favored [PSI+] over [psi-] was not reproducible by another group using the same strains (144). It is reported that certain stress conditions induce the appearance of [PSI+] in a strain with a Sup35 prion domain modified to make it more likely to convert to the prion form (145). However, those conditions did not induce [PSI+] generation in a strain with the normal Sup35 prion domain (146).

Without a dramatic benefit, however, it may be impossible to answer the question of 'bane or benefit' by this approach. Even if a modest benefit or induction of [PSI+] under some condition were reproducible, it would be nearly impossible to ascertain what is the representation of such condition in the ecological niche of yeast. Other approaches are needed.

\section{[PSI+] and [URE3] are rare in wild cells, but [Het-s] is common.}

Even a detrimental or lethal virus, plasmid or prion can be found in the wild, because the spread of the infectious element outruns the damage done to the host. Chronic wasting disease is a uniformly fatal prion disease found in $~ 10 \%$ of wild elk and deer in parts of the western US (147). Certainly a beneficial prion (or plasmid or virus) would be found in most wild individuals, and a prion being rare would be clear evidence that it is detrimental. We surveyed 70 wild Saccharomyces isolates and found that while all of the several parasitic nucleic acid replicons were found in some fraction of the strains, none had [URE3] or [PSI +], and only 11 of 70 had [PIN+] (148). A larger more recent survey confirmed the rarity of 
[PSI+] and gave an even lower estimate of the incidence of [PIN+], although [URE3] was not tested (149).

All of these infectious elements of $S$. cerevisiae spread only by outcross mating, so the validity of the argument in the previous paragraph relies on the degree to which such matings occur. Previous estimates of this frequency, using population genetic methods, were that such matings occur only once or twice per $10^{5}$ mitotic doublings, or, as one author states, only about once per 100 years $(150,151)$. We re-examined this issue from a different viewpoint. An infectious element found in wild strains spreads only by outcross mating, and this spread must balance the harm caused to the host to give the observed incidence (146) (Fig. 6). The $2 \mu$ DNA plasmid is known to slow cell growth by 1-3\% (152-154), an effect that we confirmed (146). Nonetheless, $2 \mu$ DNA was found in 38 of 70 wild isolates (148), indicating that yeast must mate at least once per 100 mitotic doublings, or 1000 times more often than had previously been estimated (146). The same equations imply that a prion found in $1 \%$ of wild strains must impart a $>1 \%$ growth/survival defect on its host (146). This constitutes a substantial detriment in the wild, but it must be noted that this is the detriment of the mildest form of each prion. As discussed below, lethal and near-lethal variants of [PSI + ] and [URE3] comprise a substantial proportion of the respective prion isolates, and of course these confer a much greater detriment on the host.

The [Het-s] prion of Podospora anserina is found in $>90 \%$ of wild isolates with the het-s allele (155), as one would predict for this apparently adaptive prion. However, the [Het-s] prion also is involved in a meiotic drive system, in which sexual crosses of the type female het-s [Het-s] x male het-S results in lethality of spores carrying the het-S allele (156). Whether the [Het-s] prion is a net benefit through its heterokaryon incompatibility function, or a net detriment through meiotic drive, one can say that the HET-s protein is certainly evolved to be a prion. A protein evolved to be a prion should have only one prion variant, adapted to its function, and that is true of [Het-s] (reviewed by (38)). This contrasts with the yeast prions, each known to have multiple variants with dramatically different properties. A knee only bends in one way, but there are many ways to break a leg.

\section{Lethal variants of yeast prions.}

The variants of [PSI+], [URE3] or other prions studied by yeast geneticists have been, necessarily, those which are not lethal to their hosts. For example, the translation termination activity of Sup35p is essential for cell growth, and an amyloid of Sup35p whose affinity for the soluble form of the protein was sufficiently high would inactivate too much of the protein and kill the cells.

To isolate such "sui $\psi$ dal [PSI+]" we constructed a strain in which a $U R A 3 C E N$ plasmid expressed a low level of Sup35C, lacking the prion domain, but able to support growth of a cell (157). Cells with suiqdal [PSI+] would now survive, but could not afford to lose the plasmid expressing Sup35C. This revealed that over half of [PSI+] isolates in this screen were either sui $\psi d a l$ [PSI+] or extremely sick, forming only tiny colonies (157). However, such a screen recovers only a fraction of lethal prions, those that depleted Sup35p too much. A prion whose amyloid had a toxic action on the cell, disrupting some important process, would kill the cells even if Sup35C were supplied. 
Ure $2 p$ is not an essential protein, and in some genetic backgrounds a ure $2 \Delta$ does not even slow cell growth. Using such a strain, we noted that many very slow-growing [URE3] isolates could be found on selective media. These strains recover normal growth when they lose the [URE3] prion. Thus, there are clearly toxic prions, and future work will be directed to understand the mechanisms of such toxicity.

It should be noted that several other lines of evidence point toward toxicity of a [PSI+] variant that would normally be relatively mild. [PSI+] decreases the fitness of $r k r 1 \Delta$ cells defective in protein quality control (158). Certain mutations in the Hsp40 Sis1p do not impair its essential function but do result in [PSI+] being lethal for the cell (117). The combined presence of [PSI+] and [PIN+] is lethal in sla2 $\Delta$ cells (159). Over expression of Sup35NM is lethal in [PSI+] cells because, like sui $\psi$ dal [PSI+] it sequesters the Sup35p, while over expression of full length Sup35p is lethal in [PSI+] cells by sequestering all of the Sup45p, the other subunit of the translation termination factor (160). [PIN+] toxicity likewise becomes evident on over expression of Rnq1p, in this case by sequestration of Spc42, a component of the spindle pole body (161). These phenomena are suggestive of possible mechanisms that may be operative in the toxicity of yeast prions without other mutations or protein over expression conditions.

MOD5 encodes a tRNA isopentenyltransferase, and $\bmod 5 \Delta$ mutations slow cell growth but make them resistant to antifungal drugs of the fluconazole group that block ergosterol biosynthesis (162). The mod5 $5 \Delta$ mutants use less isopentenyl donor units, freeing it for use in ergosterol biosynthesis (162). The [MOD] prion, by inactivating the prion protein, Mod5p, has the same effect (14). It seems unlikely that fluconazole drugs are sufficiently abundant in the yeast ecological niche to make this resistance sufficiently advantageous to offset the growth defect. Growth of cells in the presence of fluconazole enriches [MOD]-carrying cells, but it is not clear whether it induces the appearance of the prion as suggested (14).

\section{Prion-forming ability is not conserved.}

The prion domains of Sup35 proteins of several non-S. cerevisiae yeasts can support [PSI+] formation in cerevisiae when fused to the cerevisiae Sup35C (163-166), suggesting that prion - forming ability is conserved, often interpreted as evidence that prion-forming ability is an advantage. However, [URE3] formation occurs in some non-cerevisiae species, but not in others (61, 167-170). For example, the Ure2p of Candida albicans can form a [URE3] prion in $S$. cerevisiae, but that of Candida glabrata cannot, even though the latter is more closely related in sequence to the cerevisiae Ure $2 p(170)$, and the Ure2p of $S$. castellii could not form [URE3] or be infected by that of other Saccharomyces species (61). Using $S$. cerevisiae as a test bed for prion formation is certainly much easier than engineering other species to reveal prion formation, but the variation in properties of the chaperones and other cellular components involved in prion generation and propagation makes this a risky business. Notably, Aigle's group showed that the Ure2p of Kluyveromyces lactis could not form a prion at detectable frequency in K. lactis itself (169), and Ure2p of $C$. glabrata cannot form [URE3] in C. glabrata (171). 


\section{Prion domains have non-prion functions.}

The N-terminal prion domain of Sup35p is not necessary for the essential translation termination function (10), but is necessary for the normal mRNA turnover process, regulating the shortening of the 3' polyA structure of mRNAs by interacting with the polyA binding protein and polyA-degrading nucleases $(16,172)$. The Ure $2 p$ prion domain likewise has a function in stabilizing the protein from degradation (15). Thus, conservation of sequence of prion domains is not an argument for selection for prion-forming ability. It could simply be selection for the normal (non-prion) function of the prion domain. Furthermore, as discussed above, randomly shuffling the prion domain of Sup35p or Ure2p does not prevent prion formation $(64,65)$. The sequence of these prions is not important for prion formation, just the amino acid content, so that even if there were selection for prionforming ability, it need not result in conservation of sequence.

\section{Prion infection induces Hsp's.}

One indication of whether yeast prions are beneficial or detrimental is the cellular reaction to infection. Introduction of [PSI+] or [URE3] induces the heat shock proteins Hsp70 and Hsp104, suggesting that the cell views the prions as a stress $(128,130)$. Sgt2p modulates effects of chaperones on yeast prions, and is proposed to be a 'sensor' of amyloid (173). Sgt2p, a protein that helps insertion of proteins into the ER membrane, is induced on infection with [PSI+] or [PIN+], and interacts with prion proteins, possibly directing prion aggregates to chaperones (173). These reactions of the cell to prion infection suggest that the cell considers these prions a problem, not a benefit.

\section{Intraspecies barriers to [PSI+] transmission.}

Wild strains of $S$. cerevisiae have an array of Sup35p prion domain sequences, roughly divided into the reference sequence (found in lab strains), the $\Delta 19$ sequence with a 19 amino acid deletion in the prion domain, and $\mathrm{E} 9$ with several changes in the $\mathrm{M}$ domain and the N109S change (84). Each of these polymorphs is capable of becoming [PSI+], but each presents a barrier to transmission of [PSI+] from either of the other polymorphs (84). The rare wild [PSI+] isolates are sensitive to these barriers, indicating that they are effective in blocking the propagation of [PSI+] (62). Heterozygosity for the residue $129 \mathrm{M} / \mathrm{VA}$ polymorphism of human PrP prevents infection with Kuru or other forms of human TSE, and Mead et al. have suggested that this protection from prion infection has produced this polymorphism (174). We proposed a similar explanation for the polymorphism of the Sup35p prion domain (84).

Yeast prion variants are most commonly classified as 'weak' or 'strong', although, as mentioned above, they may differ in many different properties. How well these other properties correlate with the weak vs. strong classification has not been widely studied. In examining the intraspecies barriers to transmission of a strong [PSI+] variant, it has been found that any of four patterns of transmission to the common polymorphs of Sup35p may occur (62). Interestingly, simple extended mitotic growth of one such transmission variant results in generation and segregation of other transmission variants, without changing the strong character of the [PSI+] (62). The rare wild [PSI+] isolates (149) were all weak, but displayed the same array of transmission variants as did the single strong strain studied (62). 
These results were interpreted as support for the "prion cloud" model proposed for mammalian prions by Collinge and by Weissmann $(175,176)$, in which a continuing process of generation of new variants and their segregation during cell growth is envisioned. The results also have important implications for structural studies: homogeneity on the strongweak scale of cells transfected with a preparation of amyloid does not imply homogeneity of structure even of the fraction of the filaments that are infectious.

\section{Amyloidoses, structure and yeast prions.}

Like the yeast prions examined to date, most amyloids involved in human diseases are found to be in-register parallel beta sheet structures (reviewed in (98)). The only known exception so far is the amyloid transthyretin whose structure is not known, but is clearly not in-register parallel (177). Transthyretin is a serum protein that transports thyroid hormone and retinol binding protein. Amyloid of transthyretin is the basis of senile amyloidosis and several inherited amyloidoses. In contrast, none of the known functional amyloids are known to have this architecture (e.g., refs. (178-180)). Pathological amyloids, including most prions, are known to be highly polymorphic, but functional amyloids or prions should preferentially adopt a single structure. Pmel17, a melanocyte protein that functions as amyloid in melanin biogenesis, appears to be an exception to this rule based on its polymorphism when amyloid formation occurs in vitro (180), but whether it is polymorphic in vivo remains to be determined.

\section{Prospects}

There are undoubtedly many more prions to be found, particularly in organisms other than the intensively studied $S$. cerevisiae. Increasingly, infectious aspects of human amyloid diseases are being uncovered $(181,182)$, and many labs now use yeast as a testing bed for finding possible mechanisms of non-prion amyloid toxicity (e.g. ref. (183)). The use of yeast to screen for anti-prion therapeutic agents has produced some promising candidates, and suggestions that a chaperone activity of ribosomes may play a role in prion propagation (184). Among many other outstanding issues are (i) the exact structural differences among different prion variants, (ii) mechanisms of toxic prion variants, (iii) mechanisms of Btn2 and Cur1 prion curing and the sites to which they move prion particles, (iv) mechanisms of Hsp104-overproduction curing of [PSI+] and why it is specific for [PSI+], (v) while the well-studied [PSI+], [URE3] and [PIN+] appear to be diseases, are there functional yeast prions, like [Het-s] of Podospora.

\section{Acknowledgements.}

This work was supported by the Intramural Program of the National Institute of Diabetes and Digestive and Kidney Diseases. The limitation of the number of references prevented our citing a number of important papers.

\section{References.}

1. Griffith JS (1967) Self-replication and scrapie, Nature 215, 1043-1044. [PubMed: 4964084]

2. Prusiner SB (1982) Novel proteinaceous infectious particles cause scrapie, Science 216, 136-144. [PubMed: 6801762] 
3. Kim J-I, Cali I, Surewicz K, Kong Q, Raymond GJ, Atarashi R, Race B, Qing L, Gambetti P, Caughey B, and Surewicz WK (2010) Mammalian prions generated from bacterially expressed prion protein in the absence of any mammalian cofactors, J. Biol. Chem 285, 14083-14087. [PubMed: 20304915]

4. Delault NR, Piro JR, Walsh DJ, Wang F, Ma J, Geoghegan JC, and Supattapone S (2012) Isolation of phosphatidylethanolamine as a solitary cofactor for prion formation in the absence of nucleic acids, Proc. Natl. Acad. Sci. USA 109, 8546-8551. [PubMed: 22586108]

5. Cox BS (1965) PSI, a cytoplasmic suppressor of super-suppressor in yeast, Heredity 20, 505-521.

6. Lacroute F (1971) Non-Mendelian mutation allowing ureidosuccinic acid uptake in yeast, J. Bacteriol 106, 519-522. [PubMed: 5573734]

7. Wickner RB (1994) [URE3] as an altered URE2 protein: evidence for a prion analog in $S$. cerevisiae, Science 264, 566-569. [PubMed: 7909170]

8. Wickner RB, Shewmaker F, Edskes H, Kryndushkin D, Nemecek J, McGlinchey R, Bateman D, and Winchester C-L (2010) Prion amyloid structure explains templating: how proteins can be genes, FEMS Yeast Res 10, 980-991. [PubMed: 20726897]

9. Wickner RB, Edskes HK, Kryndushkin DS, McGlinchey R, Bateman D, and Kelly A (2011) Prion diseases of yeast: amyloid structure and biology, Sem. Cell \& Dev. Biol 22, 469-475.

10. TerAvanesyan A, Dagkesamanskaya AR, Kushnirov VV, and Smirnov VN (1994) The SUP35 omnipotent suppressor gene is involved in the maintenance of the non-Mendelian determinant [psi +] in the yeast Saccharomyces cerevisiae, Genetics 137, 671-676. [PubMed: 8088512]

11. Masison DC, and Wickner RB (1995) Prion-inducing domain of yeast Ure2p and protease resistance of Ure2p in prion-containing cells, Science 270, 93-95. [PubMed: 7569955]

12. Masison DC, Maddelein M-L, and Wickner RB (1997) The prion model for [URE3] of yeast: spontaneous generation and requirements for propagation, Proc. Natl. Acad. Sci. USA 94, 1250312508. [PubMed: 9356479]

13. Balguerie A, Dos Reis S, Ritter C, Chaignepain S, Coulary-Salin B, Forge V, Bathany K, Lascu I, Schmitter J-M, Riek R, and Saupe S (2003) Domain organization and structure-function relationship of the HET-s prion protein of Podospora anserina, Embo J 22, 2071-2081. [PubMed: 12727874]

14. Suzuki G, Shimazu N, and Tanaka M (2012) A yeast prion, Mod5, promotes acquired drug resistance and cell survival under environmental stress, Science 336, 355-359. [PubMed: 22517861]

15. Shewmaker F, Mull L, Nakayashiki T, Masison DC, and Wickner RB (2007) Ure2p function is enhanced by its prion domain in Saccharomyces cerevisiae, Genetics 176, 1557-1565. [PubMed: 17507672]

16. Kobayashi T, Funakoshi Y, Hoshino S, and Katada T (2004) The GTP-binding release factor eRF3 as a key mediator coupling translation termination to mRNA decay, J. Biol. Chem 279, 45693 45700. [PubMed: 15337765]

17. Kochneva-Pervukhova NV, Poznyakovski AI, Smirnov VN, and Ter-Avanesyan MD (1998) Cterminal truncation of the Sup35 protein increases the frequency of de novo generation of a prionbased $\left[\mathrm{PSI}^{+}\right]$determinant in Saccharmyces cerevisiae, Curr. Genet 34, 146-151. [PubMed: 9724418]

18. Paushkin SV, Kushnirov VV, Smirnov VN, and Ter-Avanesyan MD (1996) Propagation of the yeast prion-like $\left[\mathrm{psi}^{+}\right]$determinant is mediated by oligomerization of the SUP35-encoded polypeptide chain release factor, EMBO J 15, 3127-3134. [PubMed: 8670813]

19. Patino MM, Liu J-J, Glover JR, and Lindquist S (1996) Support for the prion hypothesis for inheritance of a phenotypic trait in yeast, Science 273, 622-626. [PubMed: 8662547]

20. Edskes HK, Gray VT, and Wickner RB (1999) The [URE3] prion is an aggregated form of Ure2p that can be cured by overexpression of Ure2p fragments, Proc. Natl. Acad. Sci. USA 96, 14981503. [PubMed: 9990052]

21. King C-Y, Tittmann P, Gross H, Gebert R, Aebi M, and Wuthrich K (1997) Prion-inducing domain $2-114$ of yeast Sup35 protein transforms in vitro into amyloid-like filaments, Proc. Natl. Acad. Sci. USA 94, 6618-6622. [PubMed: 9192614] 
22. Paushkin SV, Kushnirov VV, Smirnov VN, and Ter-Avanesyan MD (1997) In vitro propagation of the prion-like state of yeast Sup35 protein, Science 277, 381-383. [PubMed: 9219697]

23. Glover JR, Kowal AS, Shirmer EC, Patino MM, Liu J-J, and Lindquist S (1997) Self-seeded fibers formed by Sup35, the protein determinant of [PSI+], a heritable prion-like factor of S. cerevisiae, Cell 89, 811-819. [PubMed: 9182769]

24. Taylor KL, Cheng N, Williams RW, Steven AC, and Wickner RB (1999) Prion domain initiation of amyloid formation in vitro from native Ure2p, Science 283, 1339-1343. [PubMed: 10037606]

25. Caston JR, Trus BL, Booy FP, Wickner RB, Wall JS, and Steven AC (1997) Structure of L-A virus: a specialized compartment for the transcription and replication of double-stranded RNA, J. Cell Biol 138, 975-985. [PubMed: 9281577]

26. Kawai-Noma S, Pack CG, Kojidani T, Asakawa H, Hiraoka Y, Kinjo M, Haraguchi T, Taguchi H, and Hirata A (2010) In vivo evidence for the fibrillar structures of Sup35 prions in yeast cells, J. Cell. Biol 190, 223-231. [PubMed: 20643880]

27. King CY, and Diaz-Avalos R (2004) Protein-only transmission of three yeast prion strains, Nature 428, 319-323. [PubMed: 15029195]

28. Tanaka M, Chien P, Naber N, Cooke R, and Weissman JS (2004) Conformational variations in an infectious protein determine prion strain differences, Nature 428, 323-328. [PubMed: 15029196]

29. Brachmann A, Baxa U, and Wickner RB (2005) Prion generation in vitro: amyloid of Ure $2 p$ is infectious, Embo J 24, 3082-3092. [PubMed: 16096644]

30. Collins SR, Douglass A, Vale RD, and Weissman JS (2004) Mechanism of prion propagation: amyloid growth occurs by monomer addition, Plos Biol 2, 1582-1590.

31. Scheibel T, Kowal AS, Bloom JD, and Lindquist SL (2001) Bidirectional amyloid fiber growth for a yeast prion determinant, Curr Biol 11, 366-369. [PubMed: 11267875]

32. Inoue Y, Kishimoto A, Hirao J, Yoshida M, and Taguchi H (2001) Strong growth polarity of yeast prion fiber revealed by single fiber imaging, J Biol Chem 276, 35227-35230. [PubMed: 11473105]

33. Zubenko GS, Park FJ, and Jones EW (1982) Genetic properties of mutations at the PEP4 locus in Saccharomyces cerevisiae, Genetics 102, 679-690. [PubMed: 6764902]

34. Roberts BT, and Wickner RB (2003) A class of prions that propagate via covalent auto-activation, Genes Dev 17, 2083-2087. [PubMed: 12923060]

35. Ball AJS, Wong DK, and Elliott JJ (1976) Glucosamine resistance in yeast I. A preliminary genetic analysis, Genetics 84, 311-317. [PubMed: 793924]

36. Brown JC, and Lindquist S (2009) A heritable switch in carbon source utilization driven by an unusual yeast prion, Genes Dev 23, 2320-2332. [PubMed: 19797769]

37. Coustou V, Deleu C, Saupe S, and Begueret J (1997) The protein product of the het-s heterokaryon incompatibility gene of the fungus Podospora anserina behaves as a prion analog, Proc. Natl. Acad. Sci. USA 94, 9773-9778. [PubMed: 9275200]

38. Saupe SJ (2011) The [Het-s] prion of Podospora anserina and its role in heterokaryon incompatibility, Sem. Cell \& Dev. Biol 22, 460-468.

39. Maddelein ML, Dos Reis S, Duvezin-Caubet S, Coulary-Salin B, and Saupe SJ (2002) Amyloid aggregates of the HET-s prion protein are infectious, Proc Natl Acad Sci U S A 99, 7402-7407. [PubMed: 12032295]

40. Derkatch IL, Bradley ME, Zhou P, Chernoff YO, and Liebman SW (1997) Genetic and environmental factors affecting the de novo appearance of the [PSI+] prion in Saccharomyces cerevisiae, Genetics 147, 507-519. [PubMed: 9335589]

41. Sondheimer N, and Lindquist S (2000) Rnq1: an epigenetic modifier of protein function in yeast, Molec. Cell 5, 163-172. [PubMed: 10678178]

42. Derkatch IL, Bradley ME, Hong JY, and Liebman SW (2001) Prions affect the appearance of other prions: the story of [PIN], Cell 106, 171-182. [PubMed: 11511345]

43. Osherovich LZ, and Weissman JS (2001) Multiple Gln/Asn-rich prion domains confer susceptibility to induction of the yeast [PSI+] prion, Cell 106, 183-194. [PubMed: 11511346] 
44. Du Z, Park K-W, Yu H, Fan Q, and Li L (2008) Newly identified prion linked to the chromatinremodeling factor Swi1 in Saccharomyces cerevisiae, Nat. Genet 40, 460-465. [PubMed: 18362884]

45. Patel BK, Gavin-Smyth J, and Liebman SW (2009) The yeast global transcriptional co-repressor protein Cyc8 can propagate as a prion, Nat. Cell Biol 11, 344-349. [PubMed: 19219034]

46. Volkov KV, Aksenova YA, Soom MJ, Sipov KV, Svitin AV, Kurischko C, Shkundina IS, TerAvanesyan MD, Inge-Vechtomov SG, and Mironova LN (2002) Novel non-Mendelian determinant involved in the control of translation accuracy in Saccharomyces cerevisiae, Genetics 160, 25-36. [PubMed: 11805042]

47. Rogoza T, Goginashvili A, Rodionova S, Ivanov M, Viktorovskaya O, Rubel A, Volkov K, and Mironova L (2010) Non-mendelian determinant [ISP+] in yeast is a nuclear-residing prion form of the global transcriptional regulator Sfp1, Proc. Natl. Acad. Sci. USA 107, 10573-10577. [PubMed: 20498075]

48. Marion RM, Regev A, Segal E, Barash Y, Koller D, Friedman N, and O'Shea EK (2004) Sfp1 is a stress- and nutrient-sensitive regulator of ribosomal protein gene expression, Proc. Natl. Acad. Sci. USA 101, 14315-14322. [PubMed: 15353587]

49. Rogoza RE, Khokhrina M, Drozdova P, and Mironova L (2011) SUP35 expression is enhanced in yeast containing [ISP+], a prion form of the transcription regulator Sfp1, Prion 5, Epub ahead of print.

50. Dihanich ME, Najarian D, Clark R, Gillman EC, Martin NC, and Hopper AK (1987) Isolation and characterization of MOD5, a gene required for isopentenylation of cytoplasmic and mitochondrial tRNAs of Saccharomyces cerevisiae, Mol. Cell. Biol 7, 177-184. [PubMed: 3031456]

51. Alberti S, Halfmann R, King O, Kapila A, and Lindquist S (2009) A systematic survey identifies prions and illuminates sequence features of prionogenic proteins, Cell 137, 146-158. [PubMed: 19345193]

52. Hongay C, Jia N, Bard M, and Winston F (2002) Mot3 is a transcriptional repressor of ergosterol biosynthetic genes and is required for normal vacuolar function in Saccharomyces cerevisiae, EMBO J 21, 4114-4124. [PubMed: 12145211]

53. Yoshikawa K, Tanaka T, Ida Y, Furusawa C, and Hirasawa T (2011) Comprehensive phenotypic analysis of single-gene deletion and overexpression strains of Saccharomyces cerevisiae, Yeast 28, 349-361. [PubMed: 21341307]

54. Merz S, and Westermann B (2009) Genome-wide deletion mutant analysis reveals genes required for respiratory growth, mitochondrial genome maintenance and mitochondrial protein synthesis in Saccharomyces cerevisiae, Genome Biol 10, R95. [PubMed: 19751518]

55. Derkatch IL, Chernoff YO, Kushnirov VV, Inge-Vechtomov SG, and Liebman SW (1996) Genesis and variability of [PSI] prion factors in Saccharomyces cerevisiae, Genetics 144, 1375-1386. [PubMed: 8978027]

56. Kushnirov VV, Kryndushkin D, Boguta M, Smirnov VN, and Ter-Avanesyan MD (2000) Chaperones that cure yeast artificial $\left[\mathrm{PSI}^{+}\right]$and their prion-specific effects, Curr. Biol 10, 14431446. [PubMed: 11102806]

57. Bradley ME, and Liebman SW (2003) Destabilizing interactions among $[P S I+]$ and $[P I N+]$ yeast prion variants, Genetics 165, 1675-1685. [PubMed: 14704158]

58. Borchsenius AS, Muller S, Newnam GP, Inge-Vechtomov SG, and Chernoff YO (2006) Prion variant maintained only at high levels of the Hsp104 disaggregase, Curr. Genet 49, 21-29. [PubMed: 16307272]

59. Kryndushkin D, Shewmaker F, and Wickner RB (2008) Curing of the [URE3] prion by Btn2p, a Batten disease-related protein, EMBO J 27, 2725-2735. [PubMed: 18833194]

60. Vishveshwara N, and Liebman SW (2009) Heterologous cross-seeding mimics cross-species prion conversion in a yeast model, BMC Biol 7, 26. [PubMed: 19470166]

61. Edskes HK, McCann LM, Hebert AM, and Wickner RB (2009) Prion variants and species barriers among Saccharomyces Ure2 proteins, Genetics 181, 1159-1167. [PubMed: 19124570]

62. Bateman D, and Wickner RB (2013) The [PSI+] prion exists as a dynamic cloud of variants, Plos Genet in press. 
63. Chang H-Y, Lin J-Y, Lee H-C, Wang H-L, and King C-Y (2008) Strain-specific sequences required for yeast prion [PSI+] propagation, Proc Natl Acad Sci U S A 105, 13345-13350. [PubMed: 18757753]

64. Ross ED, Baxa U, and Wickner RB (2004) Scrambled prion domains form prions and amyloid, Mol Cell Biol 24, 7206-7213. [PubMed: 15282319]

65. Ross ED, Edskes HK, Terry MJ, and Wickner RB (2005) Primary sequence independence for prion formation, Proc Natl Acad Sci U S A 102, 12825-12830. [PubMed: 16123127]

66. Toombs JA, Liss NM, Cobble KR, Ben-Musa Z, and Ross ED (2011) [PSI] maintenance is dependent on the composition, not the primary sequence, of the oligopeptide repeat domain, PLoS One 6, e21953. [PubMed: 21760933]

67. Parham SN, Resende CG, and Tuite MF (2001) Oligopeptide repeats in the yeast protein Sup35p stabilize intermolecular prion interactions, EMBO J 20, 2111-2119. [PubMed: 11331577]

68. Toombs JA, McCarty BR, and Ross ED (2010) Compositional determinants of prion formation in yeast, Mol. Cell. Biol 30, 319-332. [PubMed: 19884345]

69. Toombs JA, Petri M, Paul KR, Kan GY, and Ross ED (2012) De novo design of synthetic prion domains, Proc. Natl. Acad. Sci. USA in press.

70. Ross ED, Minton AP, and Wickner RB (2005) Prion domains: sequences, structures and interactions, Nat. Cell Biol 7, 1039-1044. [PubMed: 16385730]

71. Fandrich M, Fletcher MA, and Dobson CM (2001) Amyloid fibrils from muscle myoglobin, Nature 410, 165-166. [PubMed: 11242064]

72. Patel BK, and Liebman SW (2007) "Prion proof" for [PIN+]: infection with in vitro-made amyloid aggregates of Rnq1p-(132-405) induces [PIN+], J. Mol. Biol 365, 773-782. [PubMed: 17097676]

73. Tycko R (2011) Solid-state NMR studies of amyloid fibril structure, Annu. Rev. Phys. Chem 62, 279-299. [PubMed: 21219138]

74. Tycko R (2006) Molecular structure of amyloid fibrils: insights from solid-state NMR, Quart. Revs. Biophys 1, 1-55.

75. Benzinger TL, Gregory DM, Burkoth TS, Miller-Auer H, Lynn DG, Botto RE, and Meredith SC (1998) Propagating structure of Alzheimer's beta-amyloid(10-35) is parallel beta-sheet with residues in exact register, Proc Natl Acad Sci U S A 95, 13407-13412. [PubMed: 9811813]

76. Shewmaker F, Wickner RB, and Tycko R (2006) Amyloid of the prion domain of Sup35p has an in-register parallel $\beta$-sheet structure, Proc. Natl. Acad. Sci. USA 103, 19754-19759. [PubMed: 17170131]

77. Baxa U, Wickner RB, Steven AC, Anderson D, Marekov L, Yau W-M, and Tycko R (2007) Characterization of $\beta$-sheet structure in Ure 2 p1-89 yeast prion fibrils by solid state nuclear magnetic resonance, Biochemistry 46, 13149-13162. [PubMed: 17953455]

78. Wickner RB, Dyda F, and Tycko R (2008) Amyloid of Rnq1p, the basis of the [PIN $\left.{ }^{\dagger}\right]$ prion, has a parallel in-register $\beta$-sheet structure, Proc Natl Acad Sci U S A 105, 2403-2408. [PubMed: 18268327]

79. Kryndushkin DS, Wickner RB, and Tycko R (2011) The core of Ure2p prion fibrils is formed by the N-terminal segment in a parallel cross- $\beta$ structure: evidence from solid-state NMR, J. Mol. Biol 409, 263-277. [PubMed: 21497604]

80. Ngo S, Gu L, and Guo Z (2011) Hierarchical organization in the amyloid core of yeast prion protein Ure2, J. Biol. Chem epub ahead of print.

81. Shewmaker F, Kryndushkin D, Chen B, Tycko R, and Wickner RB (2009) Two prion variants of Sup35p have in-register $\beta$-sheet structures, independent of hydration, Biochemistry 48, 50745082. [PubMed: 19408895]

82. Bradley ME, and Liebman SW (2004) The Sup35 domains required for maintenance of weak, strong or undifferentiated yeast [PSI+] prions, Mol. Microbiol 51, 1649-1659. [PubMed: 15009892]

83. Toyama BH, Kelly MJ, Gross JD, and Weissman JS (2007) The structural basis of yeast prion strain variants, Nature 449, 233-237. [PubMed: 17767153]

84. Bateman DA, and Wickner RB (2012) [PSI+] prion transmission barriers protect Saccharomyces cerevisiae from infection: intraspecies 'species barriers', Genetics 190, 569-579. [PubMed: 22095075] 
85. Baxa U, Taylor KL, Wall JS, Simon MN, Cheng N, Wickner RB, and Steven A (2003) Architecture of Ure2p prion filaments: the N-terminal domain forms a central core fiber, J. Biol. Chem 278, 43717-43727. [PubMed: 12917441]

86. Diaz-Avalos R, King CY, Wall JS, Simon M, and Caspar DLD (2005) Strain-specific morphologies of yeast prion amyloids, Proc Natl Acad Sci U S A 102, 10165-10170. [PubMed: 16006506]

87. Chen B, Thurber KR, Shewmaker F, Wickner RB, and Tycko R (2009) Measurement of amyloid fibril mass-per-length by tilted-beam transmission electron microscopy, Proc. Natl. Acad. Sci. USA 106, 14339-14344. [PubMed: 19706519]

88. Sen A, Baxa U, Simon MN, Wall JS, Sabate R, Saupe SJ, and Steven AC (2006) Mass analysis by scanning transmission electron microscopy and electron diffraction validate predictions of stacked beta-solenoid model of HET-s prion fibrils, J. Biol. Chem 282, 5545-5550. [PubMed: 17178708]

89. Paravastu AK, Leapman RD, Yau WM, and Tycko R (2008) Molecular structural basis for polymorphism in Alzheimer's $\beta$-amyloid fibrils, Proc. Natl. Acad. Sci. USA 105, 18349-18354. [PubMed: 19015532]

90. Bousset L, Thomson NH, Radford SE, and Melki R (2002) The yeast prion Ure2p retains its native a-helical conformation upon assembly into protein fibrils in vitro, EMBO J 21, 2903-2911. [PubMed: 12065404]

91. Bousset L, Briki F, Doucet J, and Melki R (2003) The native-like conformation of Ure2p in fibrils assembled under physiologically relevant conditions switches to an amyloid-like conformation upon heat-treatment of the fibrils, J. Struct. Biol 141, 132-140. [PubMed: 12615539]

92. Pierce MM, Baxa U, Steven AC, Bax A, and Wickner RB (2005) Is the prion domain of soluble Ure2p unstructured?, Biochemistry 44, 321-328. [PubMed: 15628874]

93. Baxa U, Cheng N, Winkler DC, Chiu TK, Davies DR, Sharma D, Inouye H, Kirschner DA, Wickner RB, and Steven AC (2005) Filaments of the Ure2p prion protein have a cross-beta core structure, J Struct Biol 150, 170-179. [PubMed: 15866740]

94. Thual C, Komar AA, Bousset L, Fernandez-Bellot E, Cullin C, and Melki R (1999) Structural characterization of Saccharomyces cerevisiae prion-like protein Ure2, J. Biol. Chem 274, 1366613674. [PubMed: 10224139]

95. Jiang Y, Li H, Zhu L, Zhou JM, and Perrett S (2004) Amyloid nucleation and hierarchical assembly of Ure2p fibrils. Role of asparagine/glutamine repeat and non-repeat regions of the prion domains, J. Biol. Chem 279, 3361-3369. [PubMed: 14610069]

96. Loquet A, Bousset L, Gardiennet C, Sourigues Y, Wasmer C, Habenstein B, Schutz A, Meier BH, and Melki R (2009) Prion fibrils of Ure2p assembled under physiological conditions contain highly ordered, natively folded molecules, J. Mol. Biol 394, 108-118. [PubMed: 19748512]

97. Krishnan R, and Lindquist S (2005) Structural insights into a yeast prion illuminate nucleation and strain diversity, Nature 435, 765-772. [PubMed: 15944694]

98. Tycko R, and Wickner RB (2013) Molecular structures of amyloid and prion fibrils: consensus vs. controversy, Accounts of Chem. Res in press.

99. Glover JR, and Lindquist S (1998) Hsp104, Hsp70, and Hsp40: a novel chaperone system that rescues previously aggregated proteins, Cell 94, 73-82. [PubMed: 9674429]

100. Jung G, and Masison DC (2001) Guanidine hydrochloride inhibits Hsp104 activity in vivo: a possible explanation for its effect in curing yeast prions, Curr. Microbiol 43, 7-10. [PubMed: 11375656]

101. Ferreira PC, Ness F, Edwards SR, Cox BS, and Tuite MF (2001) The elimination of the yeast [PSI + prion by guanidine hydrochloride is the result of Hsp104 inactivation, Mol Microbiol 40, 1357-1369. [PubMed: 11442834]

102. Jung G, Jones G, and Masison DC (2002) Amino acid residue 184 of yeast Hsp104 chaperone is critical for prion-curing by guanidine, prion propagation, and thermotolerance, Proc. Natl. Acad. Sci. USA 99, 9936-9941. [PubMed: 12105276]

103. Chernoff YO, Lindquist SL, Ono B-I, Inge-Vechtomov SG, and Liebman SW (1995) Role of the chaperone protein Hsp104 in propagation of the yeast prion-like factor $\left[\mathrm{psi}^{+}\right.$], Science 268, 880 884. [PubMed: 7754373] 
104. Moriyama H, Edskes HK, and Wickner RB (2000) [URE3] prion propagation in Saccharomyces cerevisiae: requirement for chaperone Hsp104 and curing by overexpressed chaperone Ydj1p, Mol. Cell. Biol 20, 8916-8922. [PubMed: 11073991]

105. Ness F, Ferreira P, Cox BS, and Tuite MF (2002) Guanidine hydrochloride inhibits the generation of prion "seeds" but not prion protein aggregation in yeast, Mol. Cell. Biol 22, 5593-5605. [PubMed: 12101251]

106. Cox BS, Ness F, and Tuite MF (2003) Analysis of the generation and segregation of propagons: entities that propagate the [PSI+] prion in yeast, Genetics 165, 23-33. [PubMed: 14504215]

107. Kryndushkin DS, Alexandrov IM, Ter-Avanesyan MD, and Kushnirov VV (2003) Yeast [PSI $\left.{ }^{\dagger}\right]$ prion aggregates are formed by small Sup35 polymers fragmented by Hsp104, J. Biol. Chem 278, 49636-49643. [PubMed: 14507919]

108. Reidy M, and Masison DC (2011) Modulation and elimination of yeast prions by protein chaperones and co-chaperones, Prion in press.

109. Inoue Y, Taguchi H, Kishimoto A, and Yoshida M (2004) Hsp104 binds to yeast Sup35 prion fiber but needs other factor(s) to sever it, J Biol Chem 279, 52319-52323. [PubMed: 15448141]

110. Krzewska J, Tanaka M, Burston SG, and Melki R (2007) Biochemical and functional analysis of the assembly of full-length Sup35p and its prion-forming domain, J. Biol. Chem 282, 1679-1686. [PubMed: 17121860]

111. Helsen CW, and Glover JR (2012) Insight into molecular basis of curing of [PSI+] prion by overexpression of 104-kDa heat shock protein (Hsp104), J. Biol. Chem 287, 542-556. [PubMed: 22081611]

112. Reidy M, and Masison DC (2012) Prokaryotic chaperones support yeast prions and thermotolerance and define disaggregation machinery interactions, Genetics 192, 185-193. [PubMed: 22732191]

113. Lum R, Tkach JM, Vierling E, and Glover JR (2004) Evidence for an unfolding/threading mechanism for protein disaggregation by Saccharomyces cerevisiae Hsp104, J. Biol. Chem 279, 29139-29146. [PubMed: 15128736]

114. Tessarz P, Mogk A, and Bukau B (2008) Substrate threading through the central pore of the Hsp104 chaperone as a common mechanism for protein disaggregation and prion propagation, Mol. Microbiol 68, 87-97. [PubMed: 18312264]

115. Hung GC, and Masison DC (2006) N-terminal domain of yeast Hsp104 chaperone is dispensable for thermotolerance and prion propagation but necessary for curing prions by Hsp104 overexpression, Genetics 173, 611-620. [PubMed: 16582428]

116. Higurashi T, Hines JK, Sahi C, Aron R, and Craig EA (2008) Specificity of the J-protein Sis1 in the propagation of 3 yeast prions, Proc. Natl. Acad. Sci. USA 105, 16596-16601. [PubMed: 18955697]

117. Kirkland PA, Reidy M, and Masison DC (2011) Functions of yeast Hsp40 chaperone Sis1p dispensable for prion propagation but important for prion curing and protection from prion toxicity, Genetics 188, 565-577. [PubMed: 21555396]

118. Allen KD, Chernova TA, Tennant EP, Wilkinson KD, and Chernoff YO (2007) Effects of ubiquitin system alterations on the formation and loss of a yeast prion, J Biol Chem 282, 3004 3013. [PubMed: 17142456]

119. Reidy M, and Masison DC (2010) Sti1 regulation of Hsp70 and Hsp90 is critical for curing of Saccharomyces cerevisiae [PSI+] prions by Hsp104, Mol. Cell. Biol 30, 3542-3552. [PubMed: 20479121]

120. Moosavi B, Wongwigkam J, and Tuite MF (2010) Hsp70/Hsp90 co-chaperones are required for efficient Hsp104-mediated elimination of the yeast [PSI+] prion but not for prion propagation, Yeast 27, 167-179. [PubMed: 20014008]

121. Kryndushkin DS, Engel A, Edskes HK, and Wickner RB (2011) Molecular chaperone Hsp104 can promote yeast prion generation, Genetics 188, 339-348. [PubMed: 21467567]

122. Aguilaniu H, Gustafsson L, Gigoulet M, and Nystrom T (2003) Assymetric inheritance of oxidatively damaged proteins during cytokinesis, Science 299, 1751-1753. [PubMed: 12610228] 
123. Kaeberlein M, McVey M, and Guarente L (1999) The SIR2/3/4 complex and SIR2 alone promote longevity in Saccharomyces cerevisiae by two different mechanisms, Genes Dev 13, 2570-2580. [PubMed: 10521401]

124. Erjavec N, Larsson L, Grantham J, and Nystrom T (2007) Accelerated aging and failure to segregate damaged proteins in Sir2 mutants can be suppressed by overproducing the protein aggregation-remodeling factor Hsp104p, Genes Dev 21, 2410-2421. [PubMed: 17908928]

125. Shewmaker F, and Wickner RB (2006) Aging in yeast does not enhance prion generation, Yeast 23, 1123-11128. [PubMed: 17133618]

126. Kampinga HH, and Craig EA (2010) The HSP70 chaperone machinery: J proteins as drivers of functional specificity, Nat. Rev. Mol. Cell Biol 11, 759-592. [PubMed: 20966969]

127. Newnam GP, Wegrzyn RD, Lindquist SL, and Chernoff YO (1999) Antagonistic interactions between yeast chaperones Hsp104 and Hsp70 in prion curing, Mol. Cell. Biol 19, 1325-1333. [PubMed: 9891066]

128. Jung G, Jones G, Wegrzyn RD, and Masison DC (2000) A role for cytosolic Hsp70 in yeast [PSI + ] prion propagation and [PSI+] as a cellular stress, Genetics 156, 559-570. [PubMed: 11014806]

129. Roberts BT, Moriyama H, and Wickner RB (2004) [URE3] prion propagation is abolished by a mutation of the primary cytosolic Hsp70 of budding yeast, Yeast 21, 107-117. [PubMed: 14755636]

130. Schwimmer C, and Masison DC (2002) Antagonistic interactions between yeast [PSI+] and [URE3] prions and curing of [URE3] by Hsp70 protein chaperone Ssa1p but not by Ssa2p, Mol. Cell. Biol 22, 3590-3598. [PubMed: 11997496]

131. Sharma D, and Masison DC (2011) Single methyl group determines prion propagation and protein degradation activities of yeast heat shock protein (Hsp)-70 chaperones Ssa1p and Ssa2p, Proc. Natl. Acad. Sci. USA 108, 13665-13670. [PubMed: 21808014]

132. Chernoff YO, Newnam GP, Kumar J, Allen K, and Zink AD (1999) Evidence for a protein mutator in yeast: role of the Hsp70-related chaperone Ssb in formation, stability and toxicity of the [PSI+] prion, Mol. Cell. Biol 19, 8103-8112. [PubMed: 10567536]

133. Pearce DA, Ferea T, Nosel SA, Das B, and Sherman F (1999) Action of BTN1, the yeast ortholog of the gene mutated in Batten disease, Nat. Genet 22, 55-58. [PubMed: 10319861]

134. Malinovska L, Kroschwald S, Munder MC, Richter D, and Alberti S (2012) Molecular chaperones and stress-inducible protein-sorting factors coordinate the spaciotemporal distribution of protein aggregates, Mol. Biol. Cell 23, 3041-3056. [PubMed: 22718905]

135. Chattopadhyay S, Muzaffar NE, Sherman F, and Pearce DA (2000) The yeast model for batten disease: mutations in BTN1, BTN2, and HSP3O alter pH homeostasis, J. Bacteriol 182, 64186423. [PubMed: 11053386]

136. Kama R, Robinson M, and Gerst JE (2007) Btn2, a Hook1 ortholog and potential Batten diseaserelated protein, mediates late endosome-Golgi protein sorting in yeast, Mol. Cell. Biol 27, 605621. [PubMed: 17101785]

137. Chattopadhyay S, Roberts PM, and Pearce DA (2003) The yeast model for Batten disease: a role for Btn2p in the trafficking of the Golgi-associated vesicular targeting protein, Yif1p, Biochem. Biophys. Res. Comm 302, 534-538. [PubMed: 12615067]

138. Kaganovich D, Kopito R, and Frydman J (2008) Misfolded proteins partition between two distinct quality control compartments, Nature 454, 1088-1095. [PubMed: 18756251]

139. Specht S, Miller SBM, Mogk A, and Bukau B (2011) Hsp42 is required for sequestration of protein aggregates into deposition sites in Saccharomyces cerevisiae, J. Cell. Biol 195, 617-629. [PubMed: 22065637]

140. Kryndushkin D, Ihrke G, Piermartiri TC, and Shewmaker F (2012) A yeast model of optineurin proteinopathy reveals a unique aggregation pattern associated with cellular toxicity, Mol. Microbiol. Epub ahead of print

141. Wickner RB (1997) A new prion controls fungal cell fusion incompatibility, Proc. Natl. Acad. Sci. USA 94, 10012-10014. [PubMed: 9294153] 
142. Eaglestone SS, Cox BS, and Tuite MF (1999) Translation termination efficiency can be regulated in Saccharomyces cerevisiae by environmental stress through a prion-mediated mechanism, EMBO J 18, 1974-1981. [PubMed: 10202160]

143. True HL, and Lindquist SL (2000) A yeast prion provides a mechanism for genetic variation and phenotypic diversity, Nature 407, 477-483. [PubMed: 11028992]

144. Namy O, Galopier A, Martini C, Matsufuji S, Fabret C, and Rousset C (2008) Epigenetic control of polyamines by the prion [PSI ${ }^{\dagger}$, Nat. Cell. Biol 10, 1069-1075. [PubMed: 19160487]

145. Tyedmers J, Madariaga ML, and Lindquist S (2008) Prion switching in response to environmental stress, PLoS Biol 6, e294. [PubMed: 19067491]

146. Kelly AC, Shewmaker FP, Kryndushkin D, and Wickner RB (2012) Sex, prions and plasmids in yeast, Proc. Natl. Acad. Sci. USA 109, E2683-E2690. [PubMed: 22949655]

147. Saunders SE, Bartelt-Hunt SL, and Bartz JC (2012) Occurence, transmission, and zoonotic potential of chronic wasting disease, Emerg. Inf. Dis 18, 369-376.

148. Nakayashiki T, Kurtzman CP, Edskes HK, and Wickner RB (2005) Yeast prions [URE3] and [PSI ${ }^{+}$] are diseases, Proc Natl Acad Sci U S A 102, 10575-10580. [PubMed: 16024723]

149. Halfmann R, Jarosz DF, Jones SK, Chang A, Lancster AK, and Lindquist S (2012) Prions are a common mechanism for phenotypic inheritance in wild yeasts, Nature 482, 363-368. [PubMed: 22337056]

150. Tsai IJ, Bensasson D, Burt A, and Koufopanou V (2008) Population genomics of the wild yeast Saccharomyces paradoxus: Quantifying the life cycle, Proc Natl Acad Sci U S A 105, 49574962. [PubMed: 18344325]

151. Ruderfer DM, Pratt SC, Seidel HS, and Kruglyak L (2006) Population genomic analysis of outcrossing and recombination in yeast, Nat. Genet 38, 1077-1081. [PubMed: 16892060]

152. Futcher AB, and Cox BS (1983) Maintenance of the $2 \mu \mathrm{m}$ circle plasmid in populations of Saccharomyces cerevisiae, J Bacteriol 154, 612-622. [PubMed: 6341357]

153. Futcher B, Reid E, and Hickey DA (1988) Maintenance of the 2 micron circle plasmid of Sacharomyces cerevisiae by sexual transmission: an example of selfish DNA, Genetics 118, 411-415. [PubMed: 3284783]

154. Mead DJ, Gardner DCJ, and Oliver SG (1986) The yeast $2 \mu$ plasmid: strategies for the survival of a selfish DNA, Mol. Gen. Genet 205, 417-421. [PubMed: 3550381]

155. Debets AJ, Dalstra HJ, Slakhorst M, Koopmanschap B, Hoekstra RF, and Saupe SJ (2012) High natural prevalence of a fungal prion, Proc. Natl. Acad. Sci. USA 109, 10432-10437. [PubMed: 22691498]

156. Dalstra HJP, Swart K, Debets AJM, Saupe SJ, and Hoekstra RF (2003) Sexual transmission of the [Het-s] prion leads to meiotic drive in Podospora anserina, Proc Natl Acad Sci U S A 100, 66166621. [PubMed: 12719532]

157. McGlinchey R, Kryndushkin D, and Wickner RB (2011) Suicidal [PSI+] is a lethal yeast prion, Proc. Natl. Acad. Sci. USA 108, 5337-5341. [PubMed: 21402947]

158. Klucevsek KM, Braun MA, and Arndt KM (2012) The Paf1 complex subunit Rtf1 buffers cells against the toxic effects of [PSI+] and defects in Rkr1-dependent protein quality control in Saccharomyces cerevisiae, Genetics 191, 1107-1118. [PubMed: 22595241]

159. Gunasova EE, Ozolins LN, Bhagat S, Newnam GP, Wegrzyn RD, Sherman MY, and Chernoff YO (2006) Modulation of prion formation, aggregation and toxicity by the actin cytoskeleton in yeast, Mol. Cell. Biol 26, 617-629. [PubMed: 16382152]

160. Vishveshwara N, Bradley ME, and Liebman SW (2009) Sequestration of essential proteins causes prion associated toxicity in yeast, Mol. Microbiol 73, 1101-1114. [PubMed: 19682262]

161. Treusch S, and Lindquist S (2012) An intrinsically disordered yeast prion arrests the cell cycle by sequestering a spindle pole body component, J. Cell. Biol 197, 369-379. [PubMed: 22529103]

162. Benko AL, VAduva G, Martin NC, and Hopper AK (2000) Competition between a sterol biosynthetic enzyme and tRNA modification in addition to changes in the protein synthesis machinery causes altered nonsense suppression, Proc. Natl. Acad. Sci. USA 97, 61-66. [PubMed: 10618371] 
163. Chernoff YO, Galkin AP, Lewitin E, Chernova TA, Newnam GP, and Belenkiy SM (2000) Evolutionary conservation of prion-forming abilities of the yeast Sup35 protein, Molec. Microbiol 35, 865-876. [PubMed: 10692163]

164. Santoso A, Chien P, Osherovich LZ, and Weissman JS (2000) Molecular basis of a yeast prion species barrier, Cell 100, 277-288. [PubMed: 10660050]

165. Kushnirov VV, Kochneva-Pervukhova NV, Cechenova MB, Frolova NS, and Ter-Avanesyan MD (2000) Prion properties of the Sup35 protein of yeast Pichia methanolica, EMBO J 19, 324-331. [PubMed: 10654931]

166. Nakayashiki T, Ebihara K, Bannai H, and Nakamura Y (2001) Yeast [PSI+] "prions” that are crosstransmissible and susceptible beyond a species barrier through a quasi-prion state, Mol Cell 7, 1121-1130. [PubMed: 11430816]

167. Edskes HK, and Wickner RB (2002) Conservation of a portion of the $S$. cerevisiae Ure2p prion domain that interacts with the full - length protein, Proc. Natl. Acad. Sci. USA 99 (Suppl. 4), 16384-16391. [PubMed: 12177423]

168. Baudin-Baillieu A, Fernandez-Bellot E, Reine F, Coissac E, and Cullin C (2003) Conservation of the prion properties of Ure2p through evolution, Mol. Biol. Cell 14, 3449-3458. [PubMed: 12925776]

169. Safadi RA, Talarek N, Jacques N, and Aigle M (2011) Yeast prions: could they be exaptations? The URE2/URE3] system in Kluyveromyces lactis, FEMS Yeast Res 11, 151-153. [PubMed: 21235712]

170. Edskes HK, Engel A, McCann LM, Brachmann A, Tsai H-F, and Wickner RB (2011) Prionforming ability of Ure2 of yeasts is not evolutionarily conserved, Genetics 188, 81-90. [PubMed: 21368275]

171. Edskes HK, and Wickner RB (2013) The [URE3] prion in Candida, Euk. Cell in press.

172. Hoshino S, Imai M, Kobayashi T, Uchida N, and Katada T (1999) The eukaryotic polypeptide chain releasing factor (eRF3/GSPT) carrying the translation termination signal to the 3'-poly(A) tail of mRNA, J. Biol. Chem 274, 16677-16680. [PubMed: 10358005]

173. Kiktev DA, Patterson JC, Muller S, Bariar B, Pan T, and Chernoff YO (2012) Regulation of the chaperone effects on a yeast prion by the cochaperone Sgt2, Mol. Cell. Biol in press.

174. Mead S, Stumpf MP, Whitfield J, Beck JA, Poulter M, Campbell T, Uphill JB, Goldstein D, Alpers M, Fisher EM, and Collinge J (2003) Balancing selection at the prion protein gene consistent with prehistoric kurulike epidemics, Science 300, 640-643. [PubMed: 12690204]

175. Collinge J, and Clarke AR (2007) A general model of prion strains and their pathogenicity, Science 318, 930-936. [PubMed: 17991853]

176. Li J, Browning S, Mahal SP, Oelschlegel AM, and Weissmann C (2010) Darwinian evolution of prions in cell culture, Science 327, 869-872. [PubMed: 20044542]

177. Bateman D, Tycko R, and Wickner RB (2011) Experimentally derived structural constraints for amyloid fibrils of wild-type transthyretin, Biophys. J 101, 2485-2492. [PubMed: 22098747]

178. Wasmer C, Lange A, Van Melckebeke H, Siemer AB, Riek R, and Meier BH (2008) Amyloid fibrils of the HET-s(218-279) prion form a beta solenoid with a triangular hydrophobic core, Science 319, 1523-1526. [PubMed: 18339938]

179. Shewmaker F, McGlinchey R, Thurber KR, McPhie P, Dyda F, Tycko R, and Wickner RB (2009) The functional curli amyloid is not based on in-register parallel beta-sheet structure, J. Biol. Chem 284, 25065-25076. [PubMed: 19574225]

180. Hu K-N, McGlinchey R, Wickner RB, and Tycko R (2011) Segmental polymorphism in a functional amyloid, Biophys. J 101, 2242-2250. [PubMed: 22067164]

181. Westermark GP, and Westermark P (2010) Prion-like aggregates: infectious agents in human disease, Trends. Mol. Med 16, 501-507. [PubMed: 20870462]

182. Junker M, and Walker LC (2011) Pathogenic protein seeding in Alzheimer's disease and other neurodegenerative disorders, Ann. Neurol 70, 532-540. [PubMed: 22028219]

183. Meriin AB, Zhang X, Alexandrov IM, Salnikova AB, Ter-Avanesyan MD, Chernoff YO, and Sherman MY (2007) Endocytosis machinery is involved in aggregation of proteins with expanded polyglutamine domains, FEBS J 21, 1915-1925. 
184. Tribouillard-Tanvier D, Dos Reis S, Gug F, Voisset C, Beringue V, Sabate R, Kikovska E, Talarek N, Bach S, Huang C, Desban N, Saupe SJ, Supattapone S, Thuret J-Y, Chedin S, Vilette D, Galons H, Sanyal S, and Blondel M (2008) Protein folding activity of ribosomal RNA is a selective target of two unrelated antiprion drugs, Plos One 3, e2174. [PubMed: 18478094]

185. Nelson R, Sawaya MR, Balbirnie M, Madsen AO, Riekel C, Grothe R, and Eisenberg D (2005) Structure of the cross- $\beta$ spine of amyloid-like fibrils, Nature 435, 773-778. [PubMed: 15944695]

186. Eanes ED, and Glenner GG (1968) X-ray diffraction studies on amyloid filaments, J. Histochem. Cytochem 16, 673-677. [PubMed: 5723775]

187. Masison DC, Kirkland PA, and Sharma D (2009) Influence of Hsp70s and their regulators on yeast prion propagation, Prion 3, 65-73. [PubMed: 19556854] 


\section{Genetic criteria for a prion}

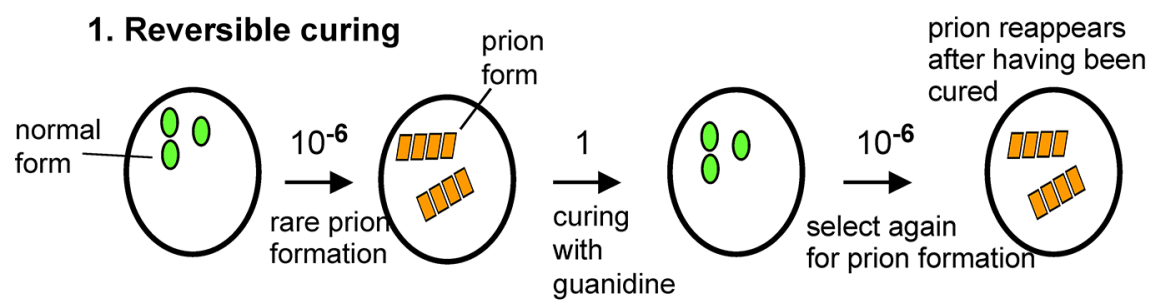

2. Prion protein overproduction increases frequency of prion appearance
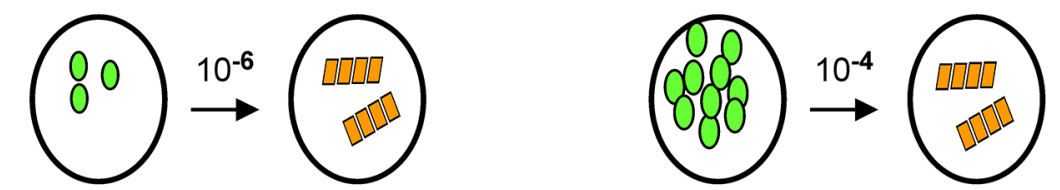

3. Similar phenotype of prion and mutant in chromosomal gene required for prion propagation

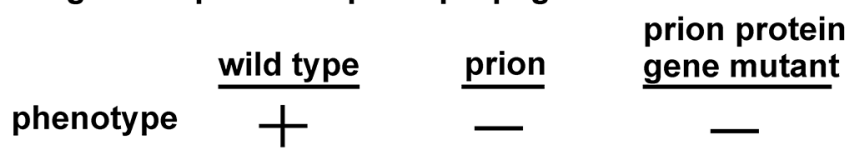

Fig. 1:

Genetic criteria for a prion (7). Modified from (8). 


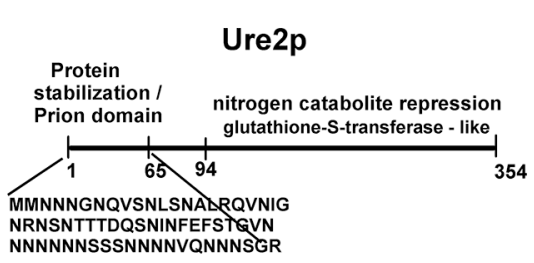

mRNA turnover $/$

Sup35p

Prion domain

repeats

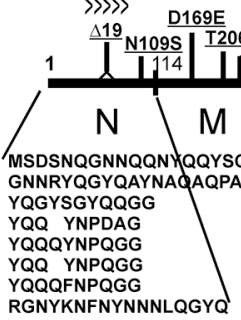

Rnq1p

Prion

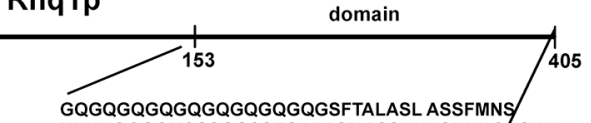

GQGQGQGQGQGQGQGQGQGSFTALASL ASSFMNS

NNNNQQGQNQSSGGSSFGALASMASSFMHSNNNGNSNN

SQQGYNQSYQNGNQN SQGYNNQQYQGGNGGYQQQQG

QSGGAFSSLASMAQSYLGGGQTQSNQQQYNQQEQNNQQ

QYQQQGQNYQHQQQGQQQQQGHSSSTALASMASSYLG

GNQNSNGQHESFNFSGNFSQQNNNGNQNRY

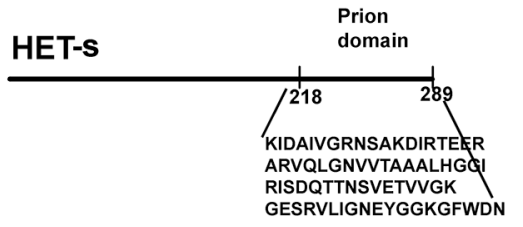

Fig. 2.

Prion domains $(10,11,13)$ have non-prion functions $(15,172)$. Prion domains of some other yeast prions have not been as well defined and their potential functions have not yet been examined in as much detail as for Sup35p and Ure2p. The prion domain of Sup35p is roughly residues 1-123 $(\mathrm{N})$, but most studies have used residues 1-254 because including the very ionic $\mathrm{M}$ domain (124-254) makes the peptide more soluble and easier to handle biochemically. The location of polymorphic changes in Sup35p affecting prion transmission are shown (84). The Ure $2 p$ prion domain includes at least residues $1-65$, but many studies include the entire unstructured $\mathrm{Q} / \mathrm{N}$ rich region, 1-89. 


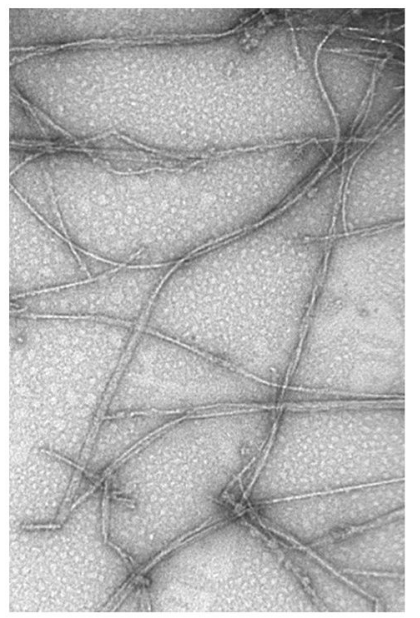

\section{C. albicans Ure2PD}

S. cerevisiae Sup35NM

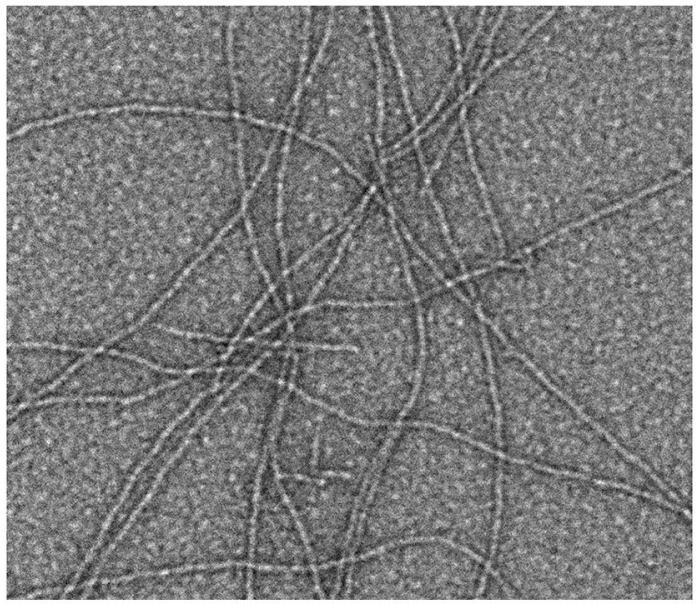

Fig. 3.

Electron micrographs of negatively stained prion amyloid filaments of the prion domains of Ure2p of Candida albicans, Sup35 of $S$. cerevisiae and HET-s of Podospora anserina, capable of transmitting [URE3albicans], [PSI+] and [Het-s], respectively. 


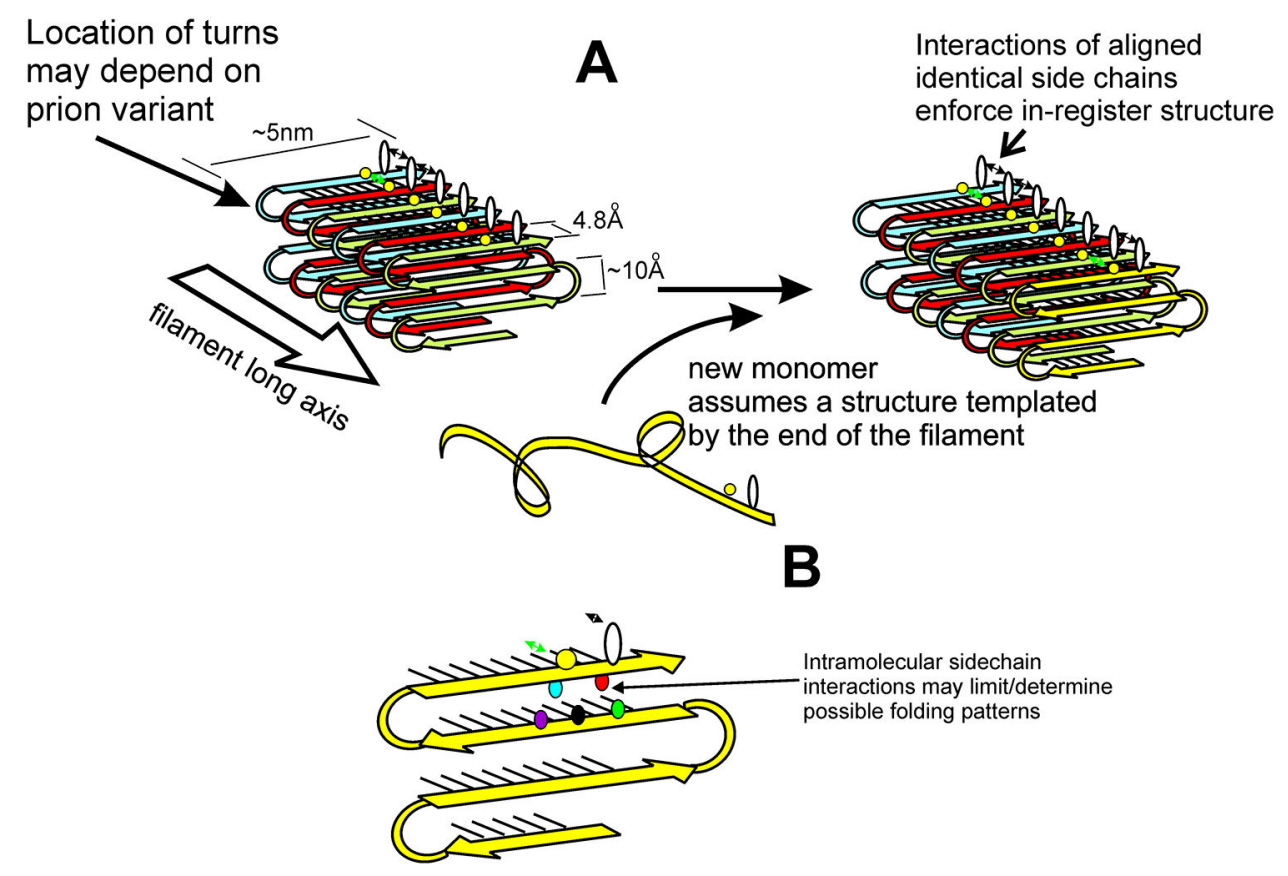

Fig. 4.

Model of folded in-register parallel beta sheet amyloid and how templating of conformation enables prion proteins to act as genes. A. The favorable intermolecular interactions between identical side chains that keep the structure in-register also force a new molecule, joining the end of a filament, to adopt the same conformation as that of other monomers in the filament. This templating of conformation is analogous to DNA templating its sequence and enables these prion proteins to act as genes. B. The locations of the folds may be restricted by the nature of the intramolecular interactions between side chains, such as those observed by Eisenberg and coworkers (185). X-ray fiber diffraction studies of various amyloids show a 'cross- $\beta$ ' pattern with a 4.75 A spacing perpendicular to a 10 A spacing (186), a pattern which has been found to be general for all amyloids. The $4.75 \mathrm{~A}$ spacing is the distance between $\mathrm{H}$-bonded $\beta$-strands, while the $\sim 10 \mathrm{~A}$ spacing is the separation distance of stacked $\beta$-sheets. 

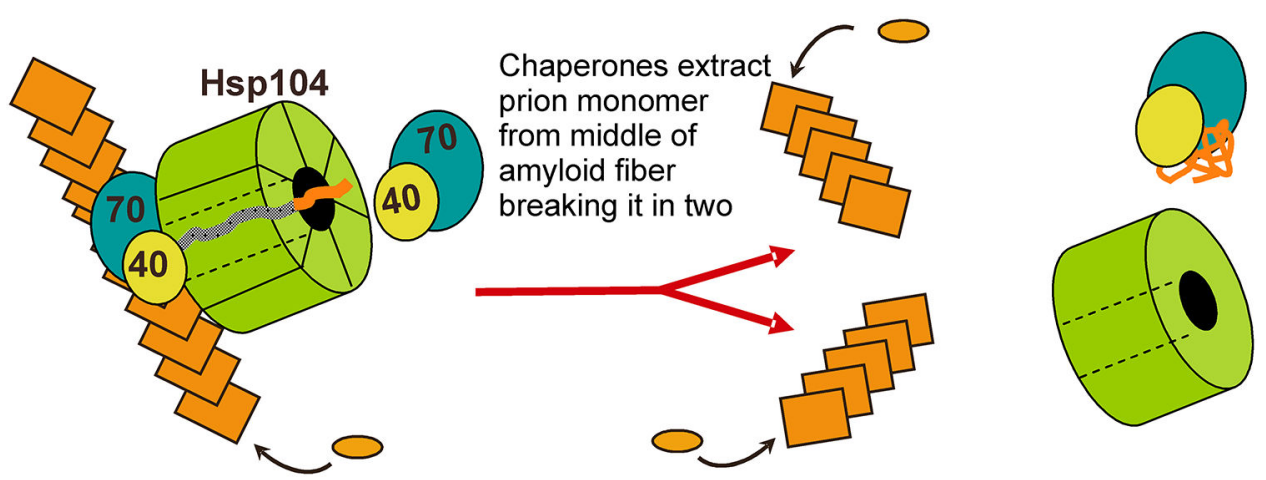

Fig. 5:

Chaperones Hsp104, Hsp70 and Hsp40 cooperating to extract a monomer from the middle of a prion filament, thereby break yeast prion amyloid filaments to make new seeds (modified from ref. (187)). 


\section{Plasmid or prion incidence is a balance of spread by mating and slowing host growth}

\section{growth slowing}

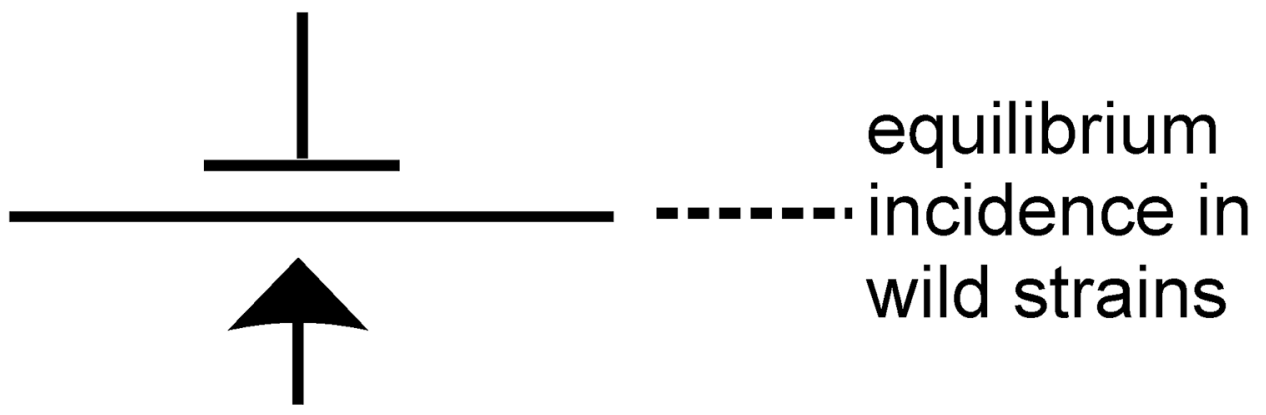

\section{spread by mating}

Fig. 6.

The incidence of a non-chromosomal genetic element (infectious element) in yeast is determined by a balance between spread by outcross matings and the slowing (or speeding) of growth (or survival) of the host resulting from the infection. The scarcity of even the mildest yeast prion variants in the wild implies they are detrimental to their hosts $(146,148)$. The 2 micron DNA plasmid is known to slow mitotic growth 1-3\% (152, 154), spread only by outcross mating, and is rarely lost. Thus, $S$. cerevisiae must have an outcross mating $\sim 1 \%$ of mitotic divisions (146). Knowing outcross mating frequency, the mildest form of [PSI+] must slow cell growth greater than $1 \%$ because it is less abundant than 2 micron DNA in wild strains (146). 